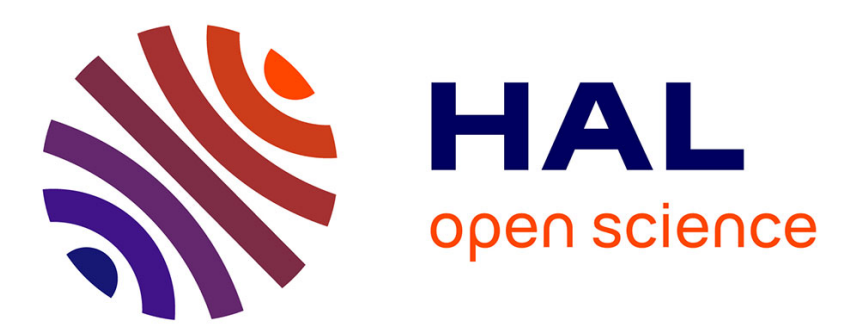

\title{
Chromatic Acclimation in Cyanobacteria: A Diverse and Widespread Process for Optimizing Photosynthesis
} Joseph E Sanfilippo, Laurence Garczarek, Frédéric Partensky, David M Kehoe

\section{To cite this version:}

Joseph E Sanfilippo, Laurence Garczarek, Frédéric Partensky, David M Kehoe. Chromatic Acclimation in Cyanobacteria: A Diverse and Widespread Process for Optimizing Photosynthesis. Annual Review of Microbiology, 2019, 73 (1), pp.407-433. 10.1146/annurev-micro-020518-115738 . hal-02322722

\section{HAL Id: hal-02322722 \\ https://hal.science/hal-02322722}

Submitted on 21 Oct 2019

HAL is a multi-disciplinary open access archive for the deposit and dissemination of scientific research documents, whether they are published or not. The documents may come from teaching and research institutions in France or abroad, or from public or private research centers.
L'archive ouverte pluridisciplinaire HAL, est destinée au dépôt et à la diffusion de documents scientifiques de niveau recherche, publiés ou non, émanant des établissements d'enseignement et de recherche français ou étrangers, des laboratoires publics ou privés. 


\section{Chromatic Acclimation in Cyanobacteria: A Diverse and Widespread Process for Optimizing Photosynthesis}

Joseph E. Sanfilippo ${ }^{1,2}$, Laurence Garczarek ${ }^{3}$, Frédéric Partensky ${ }^{3}$, and David M. Kehoe ${ }^{1^{*}}$

1. Department of Biology, Indiana University, Bloomington, Indiana, 47405 U.S.A.; emails: jsanfili@umail.iu.edu; dkehoe@indiana.edu

2. Department of Molecular Biology, Princeton University, Princeton, New Jersey, 08540 U.S.A.; email: josephes@princeton.edu

3. Sorbonne Université, CNRS, Station Biologique de Roscoff (SBR), Adaptation et Diversité en Milieu Marin (AD2M), 29680 Roscoff, France; emails: laurence.garczarek@sb-roscoff.fr;

frederic.partensky@sb-roscoff.fr

* To whom correspondence should be addressed. Department of Biology 1001 East 3rd Street Indiana University Bloomington, IN 47405 U.S.A.

E-mail: dkehoe@indiana.edu

Tel: (812) 856-4715

Fax: (812) 855-6705 


\section{ABSTRACT}

Chromatic acclimation (or CA) encompasses a diverse set of molecular processes which involve the ability of cyanobacterial cells to sense ambient light colors and use this information to optimize photosynthetic light harvesting. The six known types of CA, which we propose naming CA1 through CA6, use a range of molecular mechanisms which likely evolved independently in distantly related lineages of the Cyanobacteria phylum. Together, these processes sense and respond to the majority of the photosynthetically relevant solar spectrum, suggesting that CA provides fitness advantages in a broad range of light color niches. The recent discoveries of several new CA types suggest that additional CA systems involving additional light colors and molecular mechanisms will be revealed in coming years. Here we provide a comprehensive overview of the currently known types of CA and summarize the molecular details that underpin CA regulation.

Keywords: light regulation, photobiology, cyanobacteria, gene regulation, signal transduction photosynthesis 


\section{INTRODUCTION}

Photosynthetic organisms achieve optimum levels of photosynthetic activity by adjusting their photosynthetic machinery to changes in the amount and color of light in the environment. Chromatic acclimation (CA) is a process that modifies the composition of the light harvesting structures of many photosynthetic microbes as the ambient light color changes. CA was first described over 100 years ago $(24 ; 33 ; 34)$, when blue-green filamentous cyanobacteria collected in a European lake gradually changed color several days after being placed in the window of a laboratory. This led to the surprising discovery that the color of light to which these cyanobacteria were exposed determined their color phenotype, with red light causing the cells to turn bluegreen and green light making them brick red, and that this process was reversible. This serendipitous finding set into motion research over the past century which has revealed the molecular mechanisms underpinning $\mathrm{CA}$ as well as discoveries that have contributed to our understanding of photosynthesis, signal transduction, bacterial evolution, and global ecology. In recent years, there has been an explosion of interest in the study of CA, led by the identification of new types of CA that allow photosynthetic organisms around the world to acclimate to a diverse array of light wavelengths. Here, we blend the rich historical understanding of CA with exciting new findings while providing perspective on the shared principles between different types of CA. We also propose a newly modified naming system to classify and organize the currently known forms of CA as well as those that are likely to be discovered in the future.

The six types of CA that have been discovered to date are presented in Figure 1 and will be more fully described below. The central theme in all types of CA is the selective use of a variety of chromophores, including open-chain tetrapyrroles (or bilins) to maximize photon capture and thus the light reactions of photosynthesis. Bilin chromophores are covalently attached to specific cysteine residues of phycobiliproteins, proteins that are part of cyanobacterial photosynthetic light harvesting antennae called phycobilisomes (PBS). In general, PBS capture light wavelengths that are poorly absorbed by chlorophylls and funnel this energy into photosynthetic reaction centers. During CA, only a subset of the chromophores in PBS change. CA has most likely evolved because the absorption bandwidth of each of the different bilin chromophores used in PBS is narrow relative to the width of the irradiance spectrum used for photosynthesis and because the spectral distribution of ambient light can vary tremendously, particularly in aquatic environments (Figure 2 ) and in microbial mats $(79 ; 112)$. Thus, CA-regulated PBS changes lead to the selective use of chromophore types that maximally absorb the predominant colors (wavelengths) of the surrounding light. Under conditions of changing light colors, this strategy can capture much more photon energy to power photosynthesis than by the production of PBS with fixed chromophore types whose absorption properties may not match the predominant ambient light colors as they vary.

The substantial contribution of CA to global photosynthetic activity is becoming increasingly clear. For example, one type of CA, CA4, has been estimated to operate in about $40 \%$ of the $7 \mathrm{x}$ $10^{26}$ marine Synechococcus cells, the second most abundant photosynthetic microorganism within the world's oceans $(28 ; 42)$. CA is predicted to increase fitness in a wide range of ecological niches, including those in terrestrial, freshwater, and marine environments (Figure 2), with CAcapable and CA-incapable species or populations often coexisting $(1 ; 23 ; 36 ; 42 ; 92 ; 97 ; 117)$. CA seems to be an overwhelmingly beneficial trait to possess since it allows a portion of the PBS 
chromophore content to be adjusted to maximize energy collection for photosynthesis. This view is supported by evidence, presented below, that CA has evolved more than once. In addition, it exists in all of the major cyanobacterial lineages. However, while many cyanobacterial species are CA capable, there are also many that are not, likely because CA is a strategy that provides a fitness advantage predominantly under fluctuating light conditions (113).

The ability of CA-capable organisms to sense specific light colors and respond by producing PBS that are optimized to collect those wavelengths of light suggests that they possess sophisticated light color sensing and signal transduction systems. In this review, we will address the mechanisms and regulation of the types of CA that have been discovered thus far and examine what is known about the physiology, ecology, and evolution of these processes. Because this review is an update of a previous review on CA published in the Annual Reviews series (64), we will only briefly review CA from a historical perspective.

\section{Background: Phycobilisome Biogenesis and the Discovery of Different CA Types}

Phycobilisomes (PBS) are macromolecular light-capturing complexes that reside on the surface of the photosynthetic or thylakoid membranes. PBS structures have been extensively reviewed $(43 ; 75 ; 124)$ and so will only be summarized here. The most common PBS form is fan shaped or hemidiscoidal (Figure 3), with a central core and rods extending from the core. Both the core and rods are built of cylinders that contain phycobiliproteins and linker proteins. Phycobiliproteins are responsible for photon capture and possess one to three covalently attached chromophores that absorb specific wavelengths of light (39), while linkers predominantly lack chromophores and play structural and energy transfer roles $(72 ; 118)$. Evolution has selected the type and local environment of each chromophore within a PBS to create an energy "trap", with virtually unidirectional energy transfer through the PBS into photosynthetic reaction centers achieved by chromophores capturing higher energy, shorter wavelength photons in the outer rod regions and progressively lower energy, longer wavelength photons further down the rods and into the core (39). For every type of CA known, all chromophore substitutions maintain this energy trap.

In both the core and rods, phycobiliproteins exist as $\alpha / \beta$ heterodimers. These must be correctly chromophorylated by enzymes called phycobilin lyases, which catalyze the covalent attachment of chromophores to specific cysteines of either the $\alpha$ or $\beta$ subunit of a particular phycobiliprotein. These chromophorylation events allow the formation of the stable heterodimers that are used to build a PBS $(103 ; 126)$. Three such heterodimers form a ring-like structure, and two rings are layered together to form a disc (Figure 3). These hexameric discs, which are hollow in their centers, are then stacked into cylinders. There is a unique linker type inserted into the centers of each specific pair of discs to be joined. As will be described in the sections below, various types of CA have been found to involve the light color regulation of almost all of the above processes, including the biosynthesis of specific bilin chromophores, lyases, phycobiliproteins and linkers. In some types of CA, regulation is via a single photoreceptor that acts through its cognate transcription factor while in others, posttranscriptional regulation, multiple photoreceptors, interplay between lyases, and as-yet-undescribed mechanisms are involved.

Several additional aspects of CA physiology should be noted. First, all known forms of CA are reversible and in those that have been investigated, the most recently provided color of light 
determines the composition of the PBS. Second, the time required for a CA-mediated shift in PBS structure is dependent on the growth rate of the cells, and for the types of CA thus far tested, at least several days are required for a complete $C A$ response to occur. In addition, during CA there is no evidence that phycobiliprotein turnover rates change (8), suggesting that PBS structural changes during CA are the result of dilution of the previously existing PBS forms during cell growth and division rather than their active removal via proteolysis $(8 ; 38 ; 86)$.

In laboratories, narrow bandwidths of light are often used to determine the approximate wavelengths that are the most effective in eliciting the most extreme two "states" of a particular CA response. These "states" are when PBS are the most optimally structured to absorbing one or the other of two light colors. As described in this review, these light colors are often different for distinct types of CA, likely reflecting the different spectral niches in which various CA-capable cyanobacterial species live. Also, although all forms of CA can exist in two extreme states, if the two colors that lead to those states are both present, the PBS are composed of a mixture of the chromophores (and proteins, if applicable) from both states. It is not clear whether such heterogeneity exists within individual PBS, if there are multiple PBS types within a single cell, or if there is a mixture of cells with all of the PBS in any given cell being locked in one or the other CA state. Finally, evidence is accumulating that suggests that some cyanobacteria are capable of more than one type of CA simultaneously $(11 ; 37 ; 49)$. In such cases, complex networks of photoreceptors and signaling pathways are certainly involved.

In 1902, Gaidukov used the term "Complementary Chromatic Adaptation" to describe CA (33), since the cyanobacterial filament colors were complementary to the ambient light colors: red in green light and blue-green in red light. Seventy five years later, Tandeau de Marsac placed cyanobacteria containing the abundant phycobiliproteins phycocyanin and phycoerythrin into three groups (117). In Group 1 species, the abundance of these phycobiliprotein remained the same in red and green light, so this group does not carry out CA. Group 2 species had higher levels of phycoerythrin in green light than in red, while phycocyanin levels remained constant. Group 3 species displayed the phenotype described by Gaidukov for complementary chromatic adaptation: phycocyanin levels were high in red light and low in green light, while phycoerythrin levels were low in red light and high in green light. As described in this review, many other forms of CA have been discovered recently, but in none of these are the cell colors complementary to the eliciting light colors. Therefore, for clarity and simplicity, the word "complementary" is no longer used to describe CA.

Also, historically, Group 1 cyanobacteria were designated as those that do not undergo CA, leading to confusion about the nature of Type 1 CA or CA1. In this Review, we propose that a recently discovered form of CA be given the CA1 designation. Additionally, Group 2 is now called Type 2 CA or CA2, Group 3 is Type 3 or CA3, and all other forms of CA have been named in the chronological order of their discovery. Finally, the word "Acclimation" has replaced "Adaptation" in the name CA because adaptation requires a genetic change in an organism while acclimation does not, and no genetic change occurs during any known type of CA.

The initial description of CA3 in the early 1900s was followed by further study, mainly in the 1960s and 1970s, of CA3 photobiology. Action spectra were used to identify the wavelengths that maximally elicited CA3 (green light, approximately $541 \mathrm{~nm}$, and red light, approximately $641 \mathrm{~nm}$ ) $(21 ; 30 ; 31 ; 46 ; 47 ; 87 ; 122)$. The green-red photoreversibility of CA3 was noted to have intriguing similarity to plant red/far-red light responses controlled by phytochrome photoreceptors 
discovered in the late 1950s (13). Indeed, several decades later, a phytochrome-like histidine kinase called RcaE was identified as a green-red photoreceptor controlling the CA3 response (52; 62; 119). RcaE was the first of a new class of cyanobacterial photoreceptors named cyanobacteriochromes (CBCRs) (59), which control light responsiveness for many, but not all, types of CA through two-component phosphorelay systems.

\section{THE PHYSIOLOGY AND REGULATION OF CA SYSTEMS IDENTIFIED TO DATE}

There has been a significant increase in our awareness and understanding of many types of CA since last addressed in the Annual Reviews Series (64). In this review, we will examine the six distinct types of CA that have been identified thus far, including the between-species variation that exists for several of these types. Undoubtedly, many additional types and variations of CA remain to be discovered, underscoring the fitness benefits of tuning PBS absorption characteristics to the ambient light color environments in a wide variety of light niches and the overall importance of CA to cyanobacteria. The first three types of CA primarily respond to green and red light, the fourth to green and blue light, and the fifth and sixth to red and far-red light.

\section{CA1}

Type I chromatic acclimation (CA1) is the simplest and most recently discovered form of green/red CA. CA1 was originally identified by Masahiko Ikeuchi's group in Synechocystis sp. PCC 6803, which neither produces phycoerythrin nor undergoes the historically better-known processes of CA2 or CA3. It was identified by the discovery of a photoreceptor called CcaS, which had sequence similarity to RcaE. CcaS maximally absorbed green [wavelength $(\lambda)_{\max } 535 \mathrm{~nm}$ ] and red $\left(\lambda_{\max } 672 \mathrm{~nm}\right)$ light and was encoded near the gene encoding its cognate response regulator, $\mathrm{CcaR}$. These components were reported to be responsible for the red-green light mediated twofold change in RNA levels of $c p c G 2$, which has since been renamed $c p c L$ (125) (Figure 4A). CpcL encodes a rod-core linker that links PBS to photosystem I and leads to a redistribution of energy between the two photosystems $(20 ; 53 ; 65 ; 66)$. Since this change is occurring within the PBS, but not to either a phycobiliprotein or a chromophore, the type of CA being regulated by CcaS and CcaR in Synechocystis sp. PCC 6803 is truly a unique process compared to all other forms of $\mathrm{CA}$ that have been described. Although "CAO" was proposed for this form of CA (50), we suggest that this name is confusing because the "zero" incorrectly implies that there is no CA occurring. At the same time, we note that "CA1" currently refers to the absence of $C A$, as defined by Tandeau de Marsac (117). Thus, these names are reversed from the processes they actually designate. We propose, because linker-based CA is likely to be a major new form of CA and there was no CA type designated Group 1 CA or CA1 in the original naming (117), that the form of CA described here for Synechocystis sp. PCC 6803 be called "CA1" and that the name CA1 be used for all subsequently discovered forms of CA that involve changes in linker abundance but not in phycobiliprotein or chromophore abundances.

\section{CA2}


Type II chromatic acclimation (CA2) is a form of green/red CA identified by Nicole Tandeau de Marsac in 1977 (117). Although phycoerythrin levels were elevated in green light, there was no light color regulation of phycocyanin levels. Because of this, the color phenotypes of CA2 are more subtle than those described above for CA3 (51). The first CA2-capable cyanobacterium examined at the molecular level was Nostoc punctiforme sp. PCC 73102 (51). Its genome was found to contain a cluster of genes, one of which encoded a protein that was highly similar in sequence and photochemistry to the green/red sensing CBCR called CcaS, which controls $C p c L$ expression during CA1 in Synechocystis sp. PCC 6803. Another gene in this cluster encoded CcaR, a response regulator similar to that found to regulate $C A 1$, the phycoerythrin linker $\mathrm{CpeC}$, a rodcore linker of phycocyanin called CpcG2 or CpcL (125), and CpeR1, a protein that had been previously identified as an activator of phycoerythrin expression in the CA3 species Fremyella diplosiphon UTEX $481(16 ; 105)$. Deletion of the $N$. punctiforme ccaS led to the loss of CA2 regulation of phycoerythrin accumulation, measured as absorbance, although substantial amounts of phycoerythrin were still produced. Similarly, deletion of the $N$. punctiforme ccaR eliminated CA2-mediated phycoerythrin changes. In addition, phycoerythrin were reduced to almost undetectable levels, unlike for the ccaS mutant. Based on these results, it was proposed that CcaS acts as a phosphatase of CcaR under the non-inducing light color (51), as had been previously proposed for RcaE during CA3 (63). Northern blot analyses were also used to show that the deletion of $c c a S$ and $c c a R$ also eliminated CA2 regulation of the RNA abundance of $c p e B A$, the genes encoding the $\alpha$ and $\beta$ subunits of phycoerythrin.

Overall, it was proposed that in N. punctiforme, CcaS autophosphorylated in green light and subsequently phosphorylated $\mathrm{CcaR}$, which was found to bind a region of DNA upstream of the region of the genome encoding $c p e C, c p c G 2$ or $c p c L$ (125), and $c p e R 1$, triggering the CpeR1mediated activation of cpeBA operon expression (51) (Figure 4B). For CA2-capable species, the $\mathrm{CcaS} / \mathrm{R}$ regulators and general features of CA2 systems used in $N$. punctiforme appear to be widespread, having been found in other CA2-capable Geminocystis cyanobacteria (50) and in Gloeotrichia UTEX 583, which also shows some features of CA3-capable species (114). It was also proposed that CcaS and CcaR might make up the second system that had been identified $(3 ; 61$; $68 ; 85 ; 105)$ as one of the two CA3 regulatory pathways in $F$. diplosiphon, although this possibility was later negated by the discovery that this second system was regulated after transcription initiation (9)(see CA3 section).

\section{CA3}

Discovery and Initial Characterization. Because of the dramatic shifts between green and red cell coloration, type III chromatic acclimation (CA3) was the first type of CA to be discovered (33). It is the most complex form of green/red CA and there is evidence that it is also responsive to teal $\left(\lambda_{\max } 494 \mathrm{~nm}\right)$ and yellow $\left(\lambda_{\max } 568 \mathrm{~nm}\right)$ light (127). The initial studies of CA3 established that green and red light were the most efficient elicitors of this response (see Background) and led to the proposal that either one or two photoreceptors controlled this response (85). A single photoreceptor was expected to control both green and red light responses. If two photoreceptors were involved, one was expected to respond to green light and the other to red. Surprisingly, although current evidence suggests that two photoreceptors control CA3 (see 
below), these sense four different light colors and operate through different signal transduction pathways, making this response more exciting and novel than originally predicted.

The physiology and molecular basis of the CA3 response in different cyanobacterial species were well defined in the 1970s-2000s and have been previously reviewed $(44 ; 64)$. Thus, in this section we will only summarize the information pertinent to the CA3 model organism $F$. diplosiphon UTEX 481 (also known as Calothrix sp. PCC 7601 or Tolypothrix sp. PCC 7601) and necessary to provide context for the findings, which will be discussed in the subsequent two sections that have been made since the last reviews.

In F. diplosiphon, the differential accumulation of PBS containing phycoerythrin in green light and phycocyanin in red light, which contribute to the striking changes in cell color during CA3, are due to changes in the expression of many genes. Those that are the most critical for CA3 are shown in Figure 4C. The cpeCDESTR (hereafter $c p e C$ ) operon is more highly expressed in green light than red light $(9 ; 26 ; 27)$, with the first three genes encoding phycoerythrin-associated linkers. cpeR encodes an activator whose accumulation leads to increased expression of $c p e B A$, which encode the $\alpha$ and $\beta$ subunits of phycoerythrin (78), and $p e b A B$, the oxidoreductases required to produce phycoerythrobilin (PEB), the green-light absorbing phycoerythrin chromophore $(3 ; 29)$. Therefore, the $c p e C$ operon has a central role in coordinating green light activated gene expression during CA3. In red light, the expression of the above genes is strongly (but not completely) reduced and the $c p c B 2 A 2 H 2$ I2D2 (hereafter $c p c 2$ ) operon, encoding a CA3specific set of $\alpha$ and $\beta$ subunits of phycocyanin and phycocyanin-associated linkers, is highly upregulated $(18 ; 19 ; 73)$. Red light also upregulates the expression of $p c y A$, which encodes the oxidoreductase that produces phycocyanobilin (PCB), the red-light absorbing phycocyanin chromophore $(2 ; 29)$.

Since its discovery, there has been significant interest in how CA3 is regulated. The first CA3 signal transduction system identified was the Rca pathway (Figure $4 \mathrm{C}$ ). It is a complex type of two-component system called a phosphorelay (4) initiated by RcaE, which contains a domain with similarity to those of plant phytochromes and an output domain related to those found in histidine kinases (62). RcaE was proposed to more strongly autophosphorylate in red light than in green light, where it may have phosphatase activity $(63 ; 119)$. RcaF is a single domain response regulator that was initially proposed to be phosphorylated by RcaE (63). Genetic evidence indicates that RcaF then phosphorylates $\mathrm{RcaC}$, another response regulator that contains two receiver domains, one at its $\mathrm{N}$-terminus and one at its $\mathrm{C}$-terminus, a histidine phosphotransfer domain, and an OmpR/PhoB-class DNA binding domain $(15 ; 63)$. In red light, RcaC directly controls the repression of the $c p e C$ operon and activation of the $c p c 2$ operon and $p c y A$ by binding to the $L$ box, which is present upstream of the promoters of these genes (67). In green light, it was proposed that the reduced phosphorylation of $\mathrm{RcaC}$ decreases its binding to the $\mathrm{L}$ boxes, eliminating the activation of $c p c 2$ and $p c y A$. It also removes the repression of $c p e C$ operon expression, increasing the production of $C p e R$ and activating the expression of other green-light expressed genes such as $c p e B A$ and pebAB $(3 ; 16 ; 105)$. While the Rca system at first appeared to be capable of providing complete regulation of CA3, genetic and molecular data suggested that an additional system called the control of green light induction (Cgi) pathway substantially contributes to the control of green light expressed genes during CA3 $(3 ; 61 ; 68 ; 105)$.

In addition, in the 1970s it was noted that cell morphology, shape, and average filament length were also regulated by $\mathrm{CA} 3$ in $F$. diplosiphon (8). These observations led to the 
identification of several genes that were CA3 regulated yet predicted to encode non-PBS associated proteins. These included $c h I L N$ and $c h I B$, which are under the control of both RcaE and CpeR and encode subunits of the light-independent form of protochlorophyllide reductase, the enzyme that carries out the penultimate step in chlorophyll $a$ biosynthesis $(106 ; 115)$. Also, RcaE appears to regulate light color-dependent changes in cell morphology (10), although the expression of the putative morphogene ton $B$ increased in green light in an RcaE-independent manner (94).

Advances in Understanding the Signal Transduction and Photobiology of CA3 Regulation. Recent work has led to a better mechanistic understanding of CA3 regulation, including the Rca and Cgi pathways. RcaE was directly shown to be a green light ( $\left.\lambda_{\max } 540 \mathrm{~nm}\right)$-red light $\left(\lambda_{\max } 660\right.$ $\mathrm{nm}$ ) sensing photoreceptor that preferentially autophosphorylated in red light (52). Containing a single GAF domain as its photosensory module, it was the first identified member of the CBCR photoreceptors $(59 ; 62)$, which are now known to control many forms of CA (128).

The Cgi system has also been further defined, with studies of the region upstream of cpeC demonstrating that it regulates $c p e C$ RNA levels after transcription initiation, most likely through transcriptional attenuation in red light (9). In addition, this system represses cpeC expression in red light, so that the regulation of the $c p e C$ operon by CA3 is via two repressing systems acting in red light, the Rca system acting at the level of transcription and the Cgi pathway apparently operating by transcription attenuation. The Cgi system requires a region of the $c p e C 5^{\prime}$ leader near the start codon that is predicted to form a 30 nucleotide long stem-loop with a free energy $(\Delta G)$ of folding of $-3.4 \mathrm{kcal} / \mathrm{mol}(9)$. Even single nucleotide substitutions within this region resulted in the loss of red light repression of $c p e C$ expression. Collectively, these data suggest that an RNA binding protein may be interacting with this region, and perhaps components of the translation initiation complex, in a light-color dependent fashion.

Support for this possibility has come from a genetic screen for Cgi components that uncovered several mutants with lesions in or near infC, which encodes a translation initiation factor called IF3 (45). Traditionally an essential gene, this infC gene is dispensible in $F$. diplosiphon due to the presence of a second, diverged $\operatorname{infC}$ gene in the genome. These were named infC $a$ and inf $C b$, respectively. The deletion of infCa, but not infC $C b$, resulted in the loss of Cgi regulation of cpeC, suggesting that IF $3 \alpha$ plays a role in the Cgi regulation of CA3 (45). The position of IF3 on the $30 \mathrm{~S}$ subunit of the ribosome may allow interactions with the $c p e C 5^{\prime}$ leader stem-loop region identified as critical for Cgi system function (84). Interestingly, many plant genomes appear to encode multiple chloroplast-specific IF3s, and two have been confirmed in the model plant Arabidopsis (84). The two genes encoding these IF3s are differentially expressed developmentally and under various environmental conditions. Because the regulation of chloroplast gene expression is commonly at the level of translation initiation and involves RNA binding proteins and stem loop structures within the RNA 5' leader regions (96), related mechanisms could be at work in the regulation of the Cgi system in $F$. diplosiphon and chloroplast gene expression in plants. Many other cyanobacteria also possess multiple IF3-encoding genes, including strains which do not undergo CA (45). Thus, research on CA may have uncovered a novel form of gene regulation that is widespread throughout the Cyanobacteria.

The genetic screen that uncovered infCa also led to the identification of $d p x A$, encoding a CBCR with a GAF photosensory domain and histidine kinase output domain (127). The deletion 
of $d p x A$ led to an increased level of phycoerythrin, but not phycocyanin, in white light grown cells, suggesting that DpxA might be part of the Cgi pathway (Figure $4 C$ ). This was supported by the fact that DpxA operates through a system that is independent of the Rca pathway. The DpxA photosensory domain maximally absorbed teal and yellow light, and autophosphorylation of full length DpxA was greater in yellow light than blue light (127). In vivo, the effect of deleting $d p x A$ on increased phycoerythrin levels (measured as absorbance) was the greatest in yellow and red light, and the least in blue light. Overall, these results suggest that DpxA autophosphorylation in yellow and red light leads to the repression of phycoerythrin accumulation, and that this effect is absent in blue light. Taken together, these results make DpxA a viable candidate for the photoreceptor controlling the Cgi system, although this hypothesis has yet to be directly tested. In addition, the downstream signaling components through which DpxA acts are currently unknown. Interestingly, the DpxA absorption maxima are on the two sides of the RcaE green light absorption maximum, which is quite broad $(52 ; 127)$, suggesting that the role of DpxA, and perhaps the Cgi system, is to fine tune the levels of phycoerythrin in F. diplosiphon in the bluegreen region of the spectrum. The discovery of DpxA suggests that the regulation of CA3 involves the integration of multiple light cues and likely involves networks of photoreceptor-driven signaling pathways.

Additional Insights Into CA3-Regulated Responses Beyond the PBS. Recently, there has been additional progress in understanding how CA3 affects $F$. diplosiphon processes that are not related to PBS biogenesis $(8 ; 95)$. These light-color mediated changes in cell morphology and physiology have been found to be regulated by RcaE and include the expression of the morphogenes bolA and $m r e B(109 ; 110)$, a light-dependent iron limitation response (93), a reduction in the levels of reactive oxygen species during growth in green light (108), changes in carboxysome number, size, and structure (100), and photorespiration (80). Intriguingly, RcaE also regulates the abundance of another $F$. diplosiphon photoreceptor, a CBCR named IfIA (12). An L box with strong sequence identity to those found upstream of the $c p c 2, p c y A$, and $c p e C$ transcription start sites was found was found to overlap the iflA transcription start site. IfIA contains two photosensory GAF domains. The N-terminal GAF domain senses red light ( $\lambda_{\max } 645$ $\mathrm{nm}$ ) and far-red light $\left(\lambda_{\max } 688 \mathrm{~nm}\right)$ while the C-terminal GAF domain senses blue light $\left(\lambda_{\max } 412\right.$ $\mathrm{nm}$ ) and green light $\left(\lambda_{\max } 525 \mathrm{~nm}\right)$. IfIA also has a central, non-photosensory PHY domain (12). The role of IfIA is to increase growth when the ratio of red to far-red light in the environment is high, but because IfIA has no identifiable signaling output domain, it is not clear how it transmits its information to other sensory components in the cell. Together, the study of CA3 has revealed a network of three spectrally diverse photoreceptors, RcaE, DpxA, and IfIA, that integrate unique light color cues to optimize cell physiology and photosynthesis.

\section{CA4}

Discovery and Characterization. In 2001, Brian Palenik discovered a completely new type of CA (92), which was subsequently named type 4 chromatic acclimation (CA4) (25). Unlike CA2 and CA3, it was maximally responsive to blue and green light and specifically occurred in the unicellular marine cyanobacterium Synechococcus. This organism is broadly distributed 
throughout the world's oceans and is considered to be the second-most abundant phototroph on Earth (28). The diversification of marine Synechococcus light harvesting systems is likely an important component of their ecological success, and all known marine Synechococcus use PBS for photosynthetic light harvesting. Although some strains have phycocyanin-containing rods, most have rods with both phycocyanin and phycoerythrin, and the majority of these possess phycocyanin as well as two forms of phycoeryth rin called phycoerythrin I (PE-I) and phycoerythrin II (PE-II) $(90 ; 91$; 111). These two phycobiliproteins are related at the structural and amino acid sequence levels, but bind different chromophores and are encoded by different genes. PE-I $\alpha$ and $\beta$ subunits are encoded by the cpeBA operon and are called CpeA and CpeB, while PE-II $\alpha$ and $\beta$ subunits are encoded in the mpeBA operon and are called MpeA and MpeB. Discs made of $\mathrm{MpeA} / \mathrm{MpeB}$ heterodimers are always located at the most core-distal positions of each rod, while discs of $\mathrm{CpeA} / \mathrm{CpeB}$ heterodimers are contiguous with MpeA/MpeB discs and separated from the core by one basal phycocyanin disc. In marine Synechococcus, PE-I and PE-II often attach bluelight absorbing phycourobilin (PUB) $\left(\lambda_{\max } 495 \mathrm{~nm}\right)$ in addition to the green-absorbing PEB $\left(\lambda_{\max }\right.$ $550 \mathrm{~nm}$ ) used in CA2- and CA3-capable cyanobacteria $(58 ; 111)$.

There are three major pigment types of marine Synechococcus that contain both PE-I and PEII. The first two are blue light specialists, which have a high PUB:PEB ratio and capture blue light effectively, and green light specialists, which have a low PUB:PEB ratio and effectively absorb green light. For each of these two types, the PUB:PEB ratio is not influenced by ambient light color changes and therefore these do not undergo chromatic acclimation. The third pigment type is the blue-green generalists, also called the CA4 strains, which are capable of modifying their $P U B: P E B$ ratio in response to the ambient blue light to green light ratio $(25 ; 92)$.

The first step in understanding the mechanism and regulation of CA4 was the identification of the changes occurring in the PBS during growth in blue versus green light. Two initial discoveries made it clear that the structural basis for CA4 was different from CA1, CA2, and CA3. First, there were no detectable changes in PBS protein composition in green versus blue light during CA4. Second, it was shown in two different marine Synechococcus strains, M16.7 and RS9916, that CA4 involves chromophorylation changes at three cysteines (C), two in MpeA (C83 and $\mathrm{C140}$ ) and one in CpeA (C139), where PEB was attached in green light and PUB was attached in blue light $(25 ; 107)$. Therefore, CA4 specifically involves changes in PBS-bound chromophores, rather than changes in PBS protein subunits.

Molecular Characterization of the Genes and Proteins Involved in CA4. Comparative genomic analyses of marine Synechococcus isolates from around the world provided important and rapid insight into the process of CA4 $(58 ; 111)$. These studies found that the presence of a $4-6 \mathrm{kbp}$ genomic region with the hallmarks of a genomic island (GI) was highly correlated with CA4 capability. They also identified two phylogenetically distinct groups of CA4-capable strains with slightly different genes and gene organization within their CA4 GIs (Figure 5A). The first identified group was named CA4-A and the second CA4-B, based on the hypothesis that these would control two different but related forms of CA4.

The CA4-A gene mpeZ encoded a protein with similarity to phycobilin lyases and to the CA4$B$ mpeW gene product. Both Gls contained the genes $f c i A$ and $f c i B$, which are similar in sequence to AraC family transcription factors in their C-terminal regions. The small ORF $f c i C$ is present in all CA4-A Gls and encodes a protein related to the ribbon-helix-helix domain of some phage 
repressors (5). All CA4-A and CA4-B Gls contain unk10, while unk14 is only present in some CA4A GIs. Neither Unk10 nor Unk14 show clear sequence similarity to any known proteins.

While comparative genomics approaches provided a number of hypotheses regarding CA4 regulation, the development of methods for culturing, plating, and genetically modifying marine Synechococcus has allowed the direct testing of these hypotheses as well as the development of new ones. Specifically, genetic manipulations such as the disruption and overexpression of some the above genes have helped define their roles in CA4. Thus far, genetic analyses of CA4 have been conducted using the CA4-A model strain Synechococcus sp. RS 9916 (hereafter 9916), isolated from the Gulf of Aqaba in the Red Sea (32). Additionally, various RNA-seq, RT-PCR, and RNA blot analyses have identified CA4-responsive genes in both CA4-A and CA4-B strains, demonstrating that CA4 is regulated at least in part by mRNA abundance changes $(58 ; 102 ; 107)$. Interestingly, in 9916, only three genes, fciC, unk10, and $m p e Z$, were strongly upregulated by blue light, and all three were located within the CA4-A GI (102). Another intriguing result was that the blue light increase in mpeZ expression in a CA4-A strain was the opposite of the green light increase in mpeW expression found in a CA4-B strain $(58 ; 102 ; 107)$. This information provides an important foundation for understanding CA4 regulation and evolution, as discussed below.

CA4-A involves chromophore changes at three phycobiliprotein residues: CpeA-C139, MpeAC83, and MpeA-C140. This suggested the involvement of a phycobilin lyase, and because mpeZ appeared to encode such a lyase and was upregulated in blue light during CA4, it was the first gene disrupted in $9916(58 ; 102 ; 107)$. MpeZ was shown to be a PEB lyase-isomerase, attaching PEB to MpeA-C83 and isomerizing it to PUB (107). In a mpeZ mutant, PEB is attached to MpeAC83 in blue light, and subsequent work has shown that the lyase MpeY is responsible for this attachment (101). In wild-type cells, RNA-seq data showed that although mpeY RNA levels are not regulated by CA4, in green light they are higher than mpeZ RNA levels, while in blue light, CA4 drives the mpeZ RNA level above mpeY. Thus, it is likely that changes in the relative levels of MpeZ and MpeY determine which chromophore is attached to MpeA-C83.

The mechanisms underpinning the CA4-mediated chromophore changes at CpeA-139 and MpeA-C140 are not yet clear. In 9916, there are no other CA4-regulated genes that encode putative lyases, so additional systems similar to MpeZ/MpeY are unlikely to control the other C4driven chromophore changes. It is possible that CA4 regulation is also occurring posttranslationally, or involves the small protein encoded by CA4-regulated gene unk10, which would explain its lack of sequence relatedness to any known protein. It is also possible that Unk14 is involved, although many CA4-A capable strains do not appear to contain unk14 in the CA4 GI, making it unlikely to be an essential component of CA4-A.

Two genes within the $9916 \mathrm{Gl}$ that are not differentially expressed during CA4 are fciA and $f c i B$. Diametric phenotypes were obtained after interruption of each. A fciA mutant displayed a green light phenotype during growth in blue or green light, while a fciB mutant exhibited a blue light phenotype in either light condition (102). Because the CA4-A response upregulates three GI genes in blue light, FciA was proposed to act as an activator when the blue to green light ratio is high, while FciB acts as a repressor when the blue to green ratio is low. FciA and FciB are clearly the master regulators of CA4-A in 9916, since all CA4-based chromophorylation and gene expression phenotypes were affected in these mutants (102) (Figure 4D). Both FciA and FciB have C-terminal regions that suggest that they belong to the AraC family of transcription factors (35; 104; 121), but no DNA binding site(s) have been characterized to date. In addition, the 
mechanism(s) through which the relative amounts of blue and green light are being sensed during CA4 remains unknown. Unlike the cyanobacteria that carry out CA2 and CA3, marine Synechococcus are unlikely to use CBCRs for light color sensing since no genes encoding such proteins have been identified in the genomes of these organisms.

Why Are There Two Types of CA4? The existence of two related but different CA4 GIs is intriguing. The presence of $f c i A$ and $f c i B$ on both Gls and the similarity of $m p e Z$ and $m p e W$ suggest that these arose from a common ancestor. However, CA4-A causes the upregulation of the genes mpeZ, unk10, and fciC in blue light while CA4-B causes the upregulation of at least $m p e W$ in green light. An exciting possibility is that CA4-A GI has evolved to confer green light specialists with the capacity to use blue light effectively and that CA4-B GI has evolved to confer blue light specialists with the ability to effectively use green light. This hypothesis could be tested by transforming a series of green light specialists and blue light specialists with either the CA4-A or CA4-B GI and testing for acquisition of CA4 capability. Such experiments would provide important insights into the evolution and acquisition of this globally important trait.

Ecological Significance of CA4. One feature of CA4 that sets it apart from all other types of CA is its clear global ecological importance, although initially its prevalence in the environment was not clear. After the discovery of CA4, phenotypic screening of culture collections and analyses of published PUB:PEB ratios from the literature initially suggested that CA4-capable strains comprised up to $20 \%$ of all isolated Synechococcus strains ((42); see also http://roscoff-culturecollection.org/). However, extrapolating this projection in the field to obtain a more accurate global estimate of CA4-capable cells was problematic due to the challenge of discriminating them from other Synechococcus pigment types using a fluorescence-based approach such as flow cytometry $(17 ; 89 ; 120 ; 129)$. Although distinguishing high-PUB from low-PUB cells was possible, discriminating between blue light specialists and CA4 cells that were acclimated to blue light was impossible, as was distinguishing between green-light specialists and green light-acclimated CA4 cells. Progress in overcoming this hurdle began to be made in the last few years, when the pigment diversity of natural Synechococcus populations started to be assessed by sequencing amplicons of either the phycocyanin operon $\angle P C B A$ or the PE I operon cpeBA (130). However, while the $c P c B A$ genetic marker could discriminate Synechococcus cells containing only phycocyanin from those containing both phycocyanin and phycoeryth rin (either PE-I only or both PE-I and PE-II), it could not distinguish populations with different PUB:PEB ratios. Sequence information from the cpeBA marker, in contrast, allowed discrimination between green-light specialists containing only PE I versus those containing both PE-I and PE-II, as well as versus CA4A cells. Unfortunately, blue light specialists are phylogenetically indistinguishable from CA4-B cells using sequence information obtained with this marker $(57 ; 71 ; 130)$.

Some interesting initial findings concerning the distribution of CA4 were obtained with these markers. In the vicinity of Hong Kong, Liu et al. (71) were able to detect $c p e B A$ sequences related to that of the CA4-A strain RS9916 both in January and July at an oceanic-influenced mesotrophic coastal station (PM7) located off Port Shelter, while there were no CA4 cells at the eutrophic estuarine station NM3. Similarly, Humily et al. found that about $28 \%$ of the Synechococcus cpeBA reads retrieved from a site off the northwest French coast were from CA4-A strains, although that population was dominated by green-light specialists (63\% of total reads)(57). Xia et al. also 
analyzed surface samples from multiple cruises in the northwestern Pacific Ocean using the same primers and discovered that CA4-A cells constituted up to $100 \%$ of the Synechococcus population in subpolar waters, while green-light specialists dominated in warm, coastal waters (130).

Grébert et al. successfully constructed a global distribution map of all Synechococcus pigment types by using three different genetic markers, the $c p c B A$ and mpeBA operons and the CA4-Bspecific mpeW gene (42). Sequencing reads for these markers were recruited from the extensive metagenomic dataset collected during the Tara Oceans circumnavigation (116). For the first time, strains capable of CA4-A and CA4-B were reliably identified in field data. Globally, CA4-A strains represented $22.6 \%$ of all Synechococcus reads and CA4-B strains represented $18.9 \%$ of all Synechococcus reads and these two pigment types exhibited very complementary geographic distributions (42) (Figure 6A). CA4-A cells predominated in the nutrient-rich, temperate or cold waters found at high latitudes and in upwelling areas, while CA4-B cells were most abundant in warm, nutrient-poor waters (Figure 6B). The CA4-A phenotype was consistently strongly correlated to low temperature, high chlorophyll and high nitrate and phosphate concentrations while the CA4-B phenotype was associated with low concentrations of these two nutrients. Both forms of CA4 appeared to be globally more abundant at depth than at the surface, suggesting that CA4 provides a fitness advantage during growth at low irradiances. This finding correlates well with the previous observation that CA4-A predominates in subpolar waters (130), where irradiance levels are low throughout most of the year. The Tara Oceans data was also analyzed for the presence of other PBS biosynthesis genes (42). Surprisingly, some Synechococcus populations inhabiting the vast iron-poor areas of the Pacific Ocean that had been genetically assigned to the CA4-A group were found to possess $m p e Z$, encoding a PEB lyase-isomerase, but lacked $f c i A$ and $f c i B$, which encode the master regulators of CA4. Also missing was mpeY, encoding a PEB lyase (101). The phenotype of such cells would be that of a blue light specialist, a conclusion confirmed by the finding of an identical genomic arrangement in BIOS-E4-1, a strain isolated from iron-poor waters of the southern Pacific Ocean, which exhibits a blue light specialist phenotype. Thus, these naturally occurring CA4-A mutants appear to constitute a second type of blue light specialists, having adapted to blue, iron-depleted, ultra-oligotrophic waters by inactivating CA4, which is likely to be an energetically costly acclimation mechanism. Overall, it appears that CA4 confers a fitness benefit to Synechococcus cells in many but not all ecological niches colonized by this ubiquitous organism.

\section{CA5}

In 2009, Min Chen's group identified type V chromatic acclimation (CA5) in Acaryochloris marina, which in addition to chlorophyll $d$-based light harvesting complexes possesses non-canonical phycobiliprotein-containing light harvesting antennae that are rod shaped and contain phycocyanin and, at their base, allophycocyanin (14; 56; 77) (Figure 1). CA5 appears to be maximally responsive to far-red light ( $720 \mathrm{~nm})$ which in the strain MBIC11017 led to a loss of phycobiliproteins, while growth in red light $(\sim 625 \mathrm{~nm})$ resulted in a large increase in phycobiliprotein abundance $(23 ; 40)$. Thus, these cells appear to shift from using phycobiliprotein-based to chlorophyll $d$-based light harvesting antennae when light conditions are changed from red to far-red light. Additional studies have shown that the expression of nearly $25 \%$ of the genes in this organism's genome are differentially expressed during these light color 
shifts, and that far red light also promotes biofilm formation, with genes encoding proteins involved in cell wall and membrane biosynthesis being upregulated while many genes encoding components related to photosynthesis were downregulated (48).

Since a directed genetic system does not yet exist for $A$. marina, although transposon mutagenesis is possible (123), the signal transduction pathway(s) controlling the CA5 response have not yet been identified. One phytochrome superfamily member, AM1_5894, has been characterized from strain MBIC11017 with absorption properties in the far-red and infrared regions of the spectrum. It is a cyanobacterial member of the bacteriophytochrome family that possesses both a histidine kinase output domain and a response regulator receiver module (74). Its role, if any, in controlling CA5 remains unknown. Several CBCRs from $A$. marina have been characterized spectrally, but these do not appear to be likely candidates for CA5 photoreceptors since their in vitro reconstituted forms maximally absorb in the blue, green, and red regions of the spectrum (81-83).

\section{CA6 (FaRLIP)}

Type VI chromatic acclimation (CA6) (also known as "far-red light photoacclimation" or FaRLiP) is the most recently identified form of CA. CA6/FaRLiP was first characterized by Don Bryant's group and also operates in the far red light range. However, because the physiological responses of this form of CA are quite different from those of CA5, it is considered to be a separate form of CA, just as CA2 and CA3 both respond to green light but are considered to be separate processes because of their different cellular responses. CA6/FaRLiP has been best examined and understood in Leptolyngbya sp. JSC-1, a filamentous cyanobacterium found within a floating mat in a hot spring (11). A process that enhances the use of far red light for oxygenic photosynthesis and growth in diverse cyanobacterial species from many different environments $(6 ; 7 ; 36 ; 37 ; 41$; $60 ; 76 ; 88 ; 132)$, CA6/FaRLiP has generated strong interest in part due to the potential biotechnological applications of this process $(22 ; 128)$. This response operates by controlling the biosynthesis of both the photosynthetic apparatus and light harvesting antennae. This includes a shift in the use of different types of chlorophylls, from chlorophyll $a$ in red light to chlorophylls $f$ and $d$ in far red light, and the replacement of the core subunits of both photosystems I and II as well as the PBS (131). Additionally, the overall CA6/FaRLiP cellular response is extensive, with the expression of nearly 3,000 genes changing two-fold or more after a shift to far-red light (37). These components are encoded within a cluster of 21 genes in the genome, a genomic region that also contains genes encoding a photoreceptor and signal transduction proteins (Figure 5B).

The photoreceptor RfpA, which belongs to a distinct subgroup of knotless phytochromes (37; 98; 99) and maximally absorbs red light ( $645 \mathrm{~nm}$ ) and far-red light ( $695 \mathrm{~nm}$ ), was initially implicated in CA6/FaRLiP light sensing (37). Due to the absence of genetic tools for Leptolyngbya sp. JSC-1, several other CA6/FaRLiP-capable cyanobacterial species were used to investigate the roles of $\mathrm{RfpA}$ and two response regulators called $\mathrm{RfpB}$ and $\mathrm{RfpC}$, encoded adjacent to $\operatorname{rfp} A$ within the far-red-induced photosynthetic light harvesting complex and reaction center gene cluster, in CA6/FaRLiP (54; 132). In Chlorogloeopsis fritschii sp. PCC 9212, Chroococcidiopsis thermalis sp. PCC 7203, and Synechococcus sp. PCC 7335, all three of these proteins appear to facilitate the process of far-red light acclimation (Figure $4 \mathrm{E}$ ). $\mathrm{RfpB}$ has been proposed to act as a transcription factor, based on the similarity of one of its domains to winged-helix domains of known 
transcription factors (132). RfpC is a single-domain response regulator and thus is likely functioning as a phosphoryl group shuttle, although its role is unknown. The gene cluster implicated in conferring CA6/FaRLiP is conserved in thirteen cyanobacterial species (36). A CA6/FaRLiP-like gene cluster is also present in the cyanobacterium Halomicronema hongdechloris, which produces chlorophylls $a$ and $f$ but not chlorophyll $d$. After a shift to far-red light, this species loses its PBS rods and remodels the PBS core to contain variants of allophycocyanin that have red-shifted absorption characteristics, matching the absorption features of the chlorophyll $f$ produced in far-red light (70). Also, after shifts from white to far-red light, the chlorophyll composition of photosystem I changes from all chlorophyll $a$ to $92 \%$ chlorophyll $a$ and approximately $8 \%$ chlorophyll $f(69)$.

Interestingly, both Leptolyngbya sp. JSC-1 and Synechococcus sp. PCC 7335 also carry out CA3 (49). In Synechococcus sp. PCC 7335, loss of FaRLiP regulators affect the amount and ratios of phycocyanin and phycoerythrin (55), raising the possibility that the CA6/FaRLiP and CA3 regulatory pathways are intertwined. Further complexity is suggested by the finding that in Leptolyngbya sp. JSC-1, rfpA transcripts are most abundant in cells grown in far-red light, suggesting that either RfpA autoregulates its expression or that another photoreceptor regulates rfpA gene expression (37). CA6/FaRLiP might provide a selective light absorption advantage in far-red-enriched environments found beneath vegetation canopies, within microbial mats or in soil environments. The influence of CA6/FaRLiP is extensive in Leptolyngbya sp. JSC-1, leading to at least two-fold changes in expression of greater than $40 \%$ of genes in this organism (37). Notably, there are many differences in the downstream responses controlled by CA6/FaRLiP between Leptolyngbya sp. JSC-1 and Synechococcus sp. PCC 7335, including major differences in phycobilisome structures $(54 ; 55)$, perhaps because they are found in different environments.

\section{CONCLUDING REMARKS AND PERSPECTIVES}

In the past few decades, there has been a dramatic increase in our knowledge of the types of CA occurring in the natural environment and how they operate. We have progressed from investigating the nature of the phenotypically dramatic green-red color changes occurring during CA3 to studying processes such as CA1, which is only detectable using sophisticated molecular tools, the dual systems regulating CA3, and CA6/FaRLiP, which is useful for efficiently harvesting light for photosynthesis in the far-red region of the spectrum, colors which are beyond the ability of humans to see.

With this new knowledge has also come an expanded awareness of the diversity of the ecological niches in which the various forms of CA can be found. Free-living cells, symbionts or epiphytes in marine, freshwater, or terrestrial environments, it is now almost easier to list the type of environments in which CA-capable cyanobacteria are not known to inhabit than to name those where CA occurs. In addition, it is becoming increasingly clear that CA is a widespread mechanism for optimizing the efficiency of photon capture for photosynthesis in cyanobacteria which play important roles in the Earth's carbon and oxygen cycles. Because CA2 and CA3 were the first forms of $C A$ to be identified and both involve the adjustment of phycoerythrin levels, the initial estimate of CA frequency was made only for phycoerythrin-containing cyanobacteria (117). Approximately $27 \%$ of the strains examined from the Pasteur Culture Collection did not undergo CA2 or CA3, $16 \%$ were CA2 strains, and $57 \%$ were CA3 strains. While these data convincingly 
show the high frequency of CA in phycoerythrin-containing strains, the impact of this finding is tempered by the fact that a large but undefined percentage of cyanobacterial species do not contain phycoerythrin. The overwhelming importance and prevalence of CA in the natural environment has been brought into sharp focus recently by the discovery of CA4 $(25 ; 92)$ and the estimate that strains capable of this process make up about $40 \%$ of the $7 \times 10^{26}$ marine Synechococcus cells in the world's oceans $(28 ; 42)$. It will be important to take into account the increased effectiveness of photosynthesis that CA provides to cyanobacteria as we continue to refine global estimates of primary productivity.

Given the discoveries of several entirely novel CA types in the last decade, it is reasonable to expect continued growth in the number of new types of CA that are discovered in the coming years. This increase will almost certainly be accompanied by the identification of ever more nuanced variations of CA between species, even for particular type of CA. Such variations will have almost certainly arisen due to a combination of chance and selection for features of CA that are the most beneficial for that organism's photosynthetic toolbox and the specific light color environment in which it resides. What we have learned about CA thus far clearly shows that the various forms have predominantly evolved independently in distantly related lineages of the Cyanobacteria phylum. Yet the phenotypic plasticity provided by this process has allowed the evolution of light harvesting antennae that effectively absorb the available colors of ambient light.

As progress continues to be made in deciphering the molecular mechanisms and regulation of the different forms of CA, the next and perhaps greatest challenge will be to better understand both the fitness costs and benefits for CA-capable cyanobacteria in their natural environments. Only then will we truly understand the biology of CA.

\section{ACKNOWLEDGEMENTS}

This review is dedicated to Arthur Grossman, whose high quality research efforts and guidance helped lead the way into the molecular realm of CA. We thank members of the Kehoe laboratory, especially Lisa Wiltbank and Andrian Gutu, for helpful discussions and comments. This research was supported by National Institutes of Health Training Grant to J.E.S. (T32-GM007757), National Science Foundation Grants to D.M.K. (MCB-1029414 and MCB-1818187), by the Office of the Vice Provost for Research at Indiana University, Bloomington, through its Bridge Funding Program to D.M.K., and by the French "Agence Nationale de la Recherche" Programs SAMOSA (ANR-13ADAP-0010) for F.P. and L.G. 

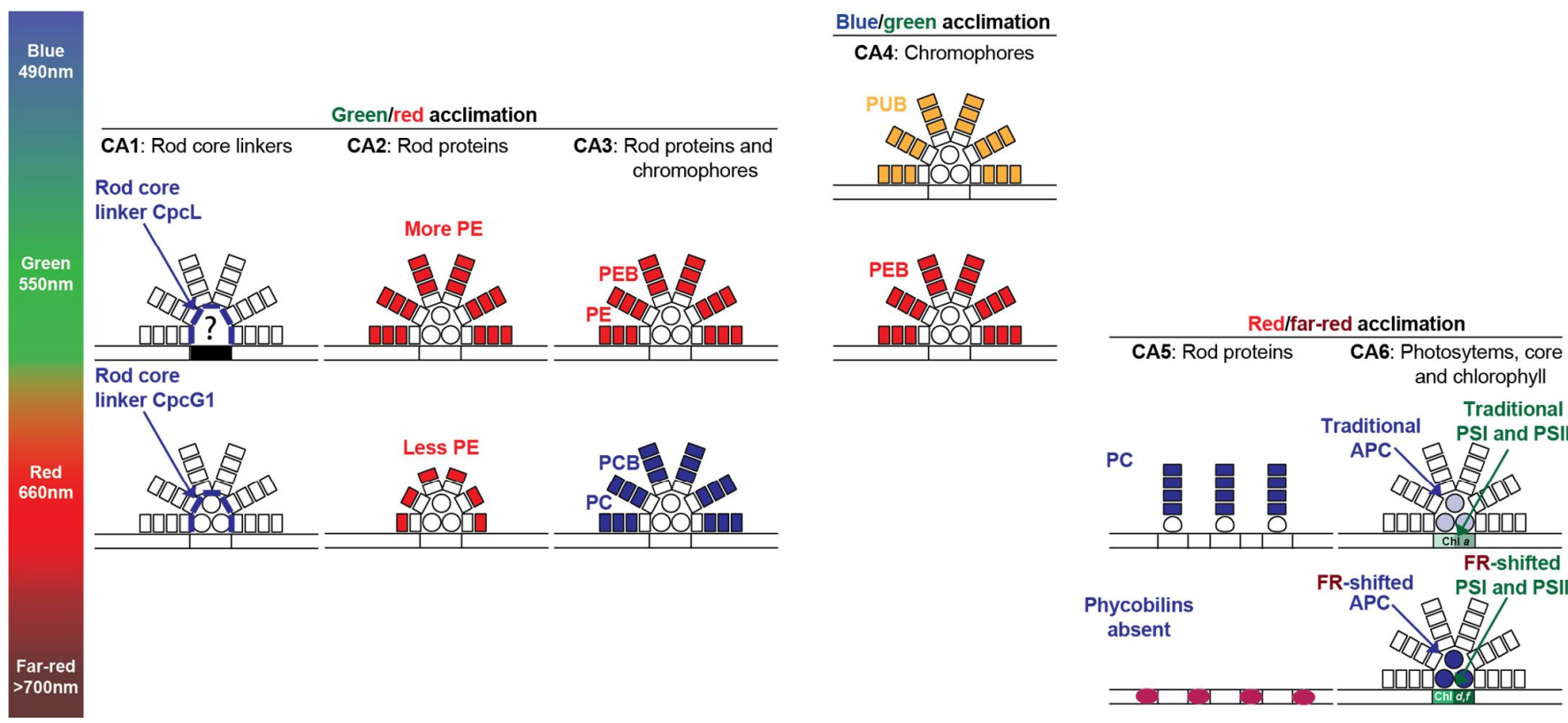

Figure 1. Simplified summary of the changes in light harvesting structures that occur during chromatic acclimation. Portions of the light harvesting structures that change during CA are shown in color, while all other aspects are shown in white for simplicity. Additionally, all of the PBS antennae are shown with the same architecture, although some small differences in protein stoichiometry and size may exist. Parallel horizontal black lines represent the photosynthetic (thylakoid) membranes with photosynthetic reaction centers demarked by two black vertical lines within thylakoid membranes. CA1, CA2, and CA3 are different forms of green/red acclimation. CA1 induces the rod core linker CpcL in green light, which appears to lead to formation of PBS without core components that preferentially associate with Photosystem I (indicated by black rectangle). It is not clear how the rods are linked to the reaction centers in this situation (question mark). CA2 induce phycoerythrin (PE) in green light, which leads to longer PBS rods. CA3 has complementary roles in inducing phycocyanin (PC) in red light and inducing PE in green light. CA3 also regulates levels of the bilin chromophores PCB and PEB, which leads to changes in the color of the PBS rods. Blue/green acclimation type CA4 changes the relative amounts of the bilin chromophores PUB and PEB, while not affecting the PBS proteins, also leading to a change in the color of the rods. CA5 leads to a loss of PC-containing phycobilins in far-red light, which are replaced by chlorophyll $d$ based light harvesting antennae in the membrane (dark red ovals). CA6 (also called FaRLiP) causes large changes in the photosynthetic apparatus in far-red light, inducing far-red shifted allophycocyanin (APC), alternate photosystem proteins, and chlorophylls $d$ and $f$. 

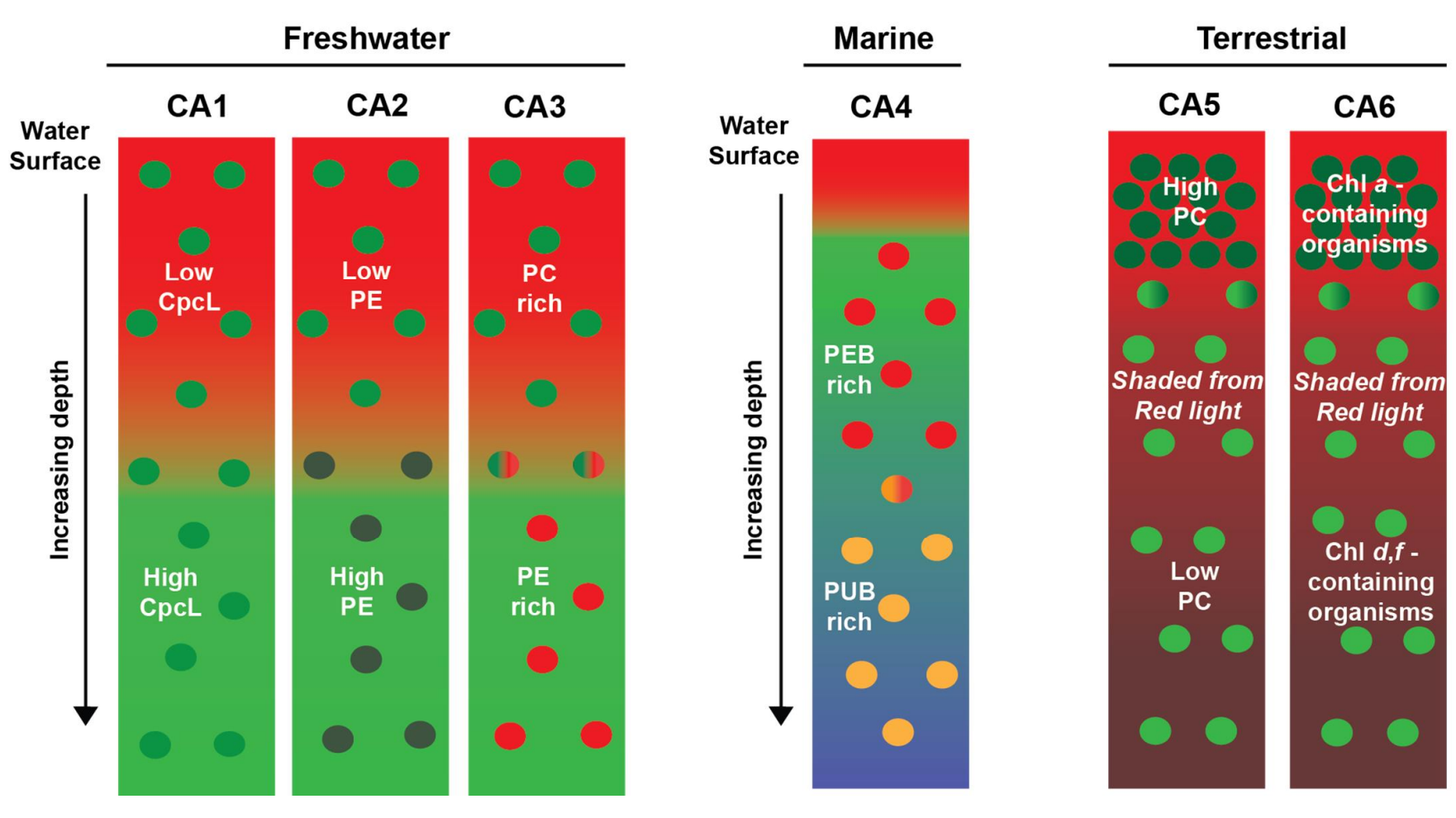

Figure 2. Chromatic acclimation is predicted to function across diverse ecological niches. Green/red acclimation types CA1, CA2, and CA3 likely function predominantly in environments where red and green wavelengths predominate. CA1 induces the rod core linker CpcL in green light, while $C A 2$ and $C A 3$ serve to induce phycoerythrin (PE) in green light. CA3 has a complementary role in inducing phycocyanin (PC) in red light. Blue/green acclimation type CA4 changes the relative amounts of the bilin chromophores PUB and PEB in marine environments where a natural gradients of green and blue light occur between costal and offshore environments or between surface and deep waters. Red/far-red acclimation types CA5 and CA6 (also called FaRLiP) likely function frequently in terrestrial environments, where dense surface populations of chlorophyll $a$-containing organisms create shaded conditions with little to no available red light below them. CA5 serves to reduce expression of phycocyanin (PC) in far-red light, while CA6/FaRLiP leads to the induction of far-red optimized core proteins, photosystems, and chlorophylls. 

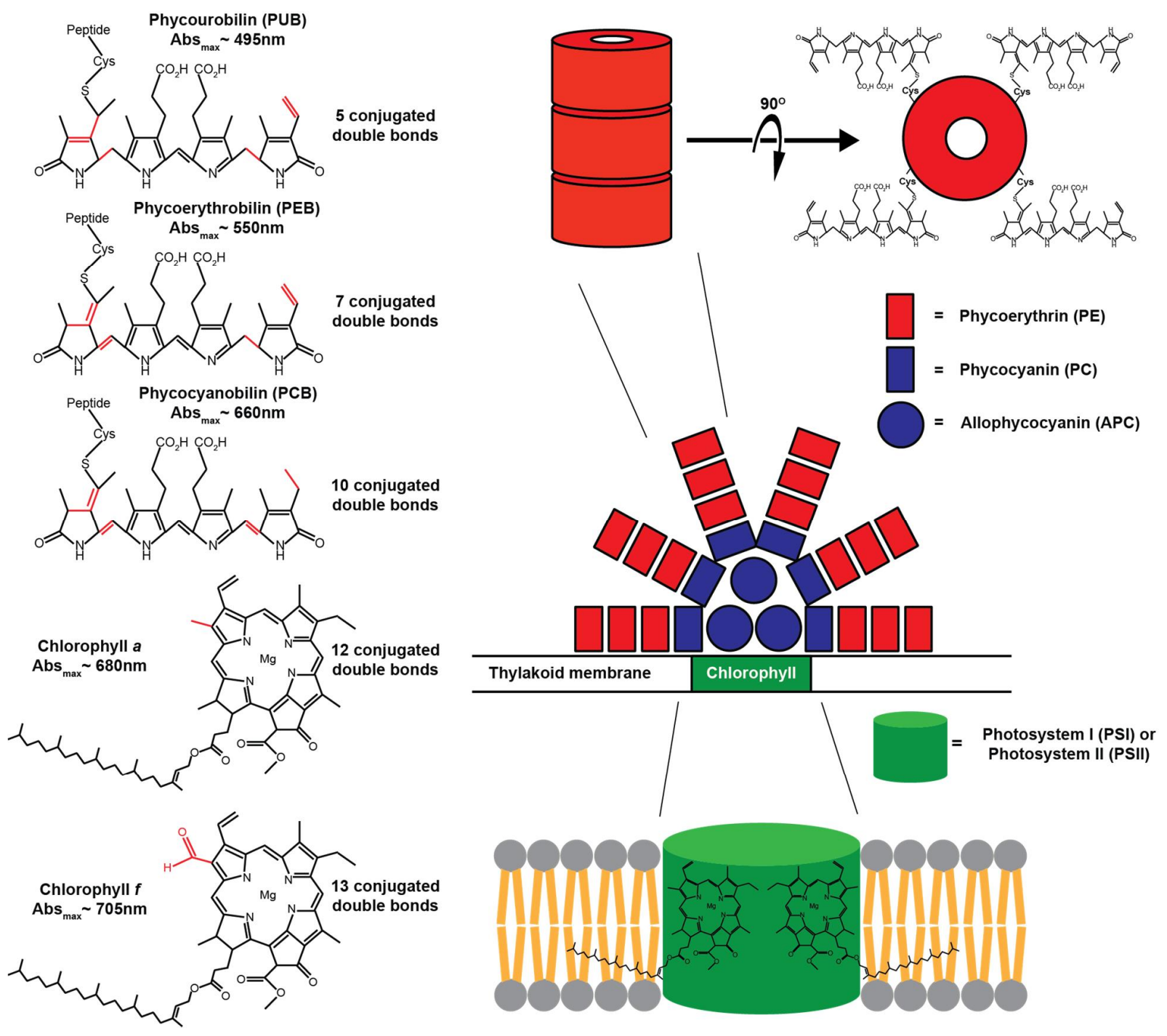

Figure 3. Light harvesting molecules involved in chromatic acclimation. (Top Left) Chemical structures of the bilin chromophores phycourobilin (PUB), phycoerythrobilin (PEB), and phycocyanobilin $(\mathrm{PCB})$ chromophores with differences between these isomers denoted in red. (Top Right) Bilin chromophores are attached to cysteine residues on phycobiliproteins through thioether linkages. (Bottom Right) Detail of the spatial arrangement between a phycobilisome and a photosynthetic reaction center. (Bottom Left) Chemical structures of chlorophyll $a$ and $f$ found in photosynthetic reaction centers, with differences between the structures denoted in red. Chlorophyll is associated with photosystem II or I proteins and is embedded in the thylakoid membrane by a large hydrophobic tail. 

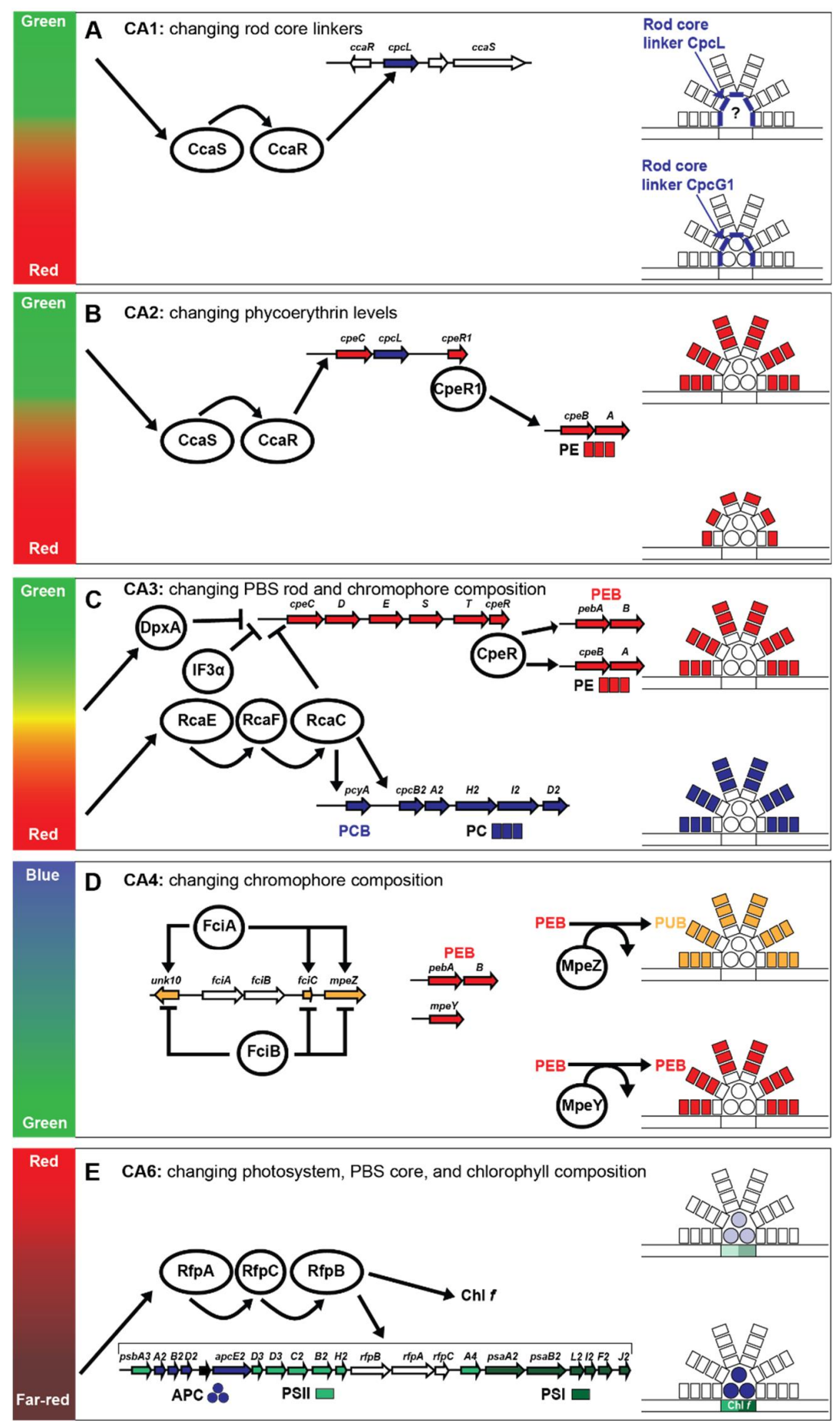

Figure 4. Regulatory mechanisms controlling chromatic acclimation. (A and $B$ ) Signaling pathways controlling CA1 in Synechocystis sp. PCC 6803 and CA2 in Nostoc punctiforme sp. PCC 73102 both involve the CBCR CCaS and response regulator CcaR but regulate different physiological responses (see Figure 1). (C) Red/green CA3 in Fremyella diplosiphon UTEX 481 uses the CBCR RcaE and two response regulators, RcaF and RcaC, to regulate the composition of the rod proteins and chromophore composition (PEB or PCB). The Cgi pathway also represses production of phycoerythrin-containing rods and involves repression by an IF3 translation initiation factor. A candidate CBCR for the Cgi photosensor is DpxA, a histidine kinase that 
represses phycoerythrin expression in yellow light. (D) The blue-green CA4 system (CA4-A is shown) in Synechococcus sp. RS9916 regulates PUB and PEB levels in the rods, is inversely regulated by $\mathrm{FciA}$ and $\mathrm{FciB}$, two proteins with similarity to AraC-class transcription factors. (E) During CA6 (also called FaRLiP) in Leptolyngbya sp. JSC-1, variation in expression of a cluster of genes changes the chlorophyll content (chl $a$ or $\mathrm{chl} d / f$ ) and the type of allophycocyan in (APC), photosystem II (PSII), and photosystem I (PSI) present in the core and is regulated by the phytochrome superfamily member $\mathrm{RfpA}$ and two response regulators, $\mathrm{RfpB}$ and $\mathrm{RfpC}$. Responses during CA1, CA2, CA3, and CA6/FaRLiP have all been shown to involve photoreceptors with histidine kinase activity through two-component systems or phosphorelay. 

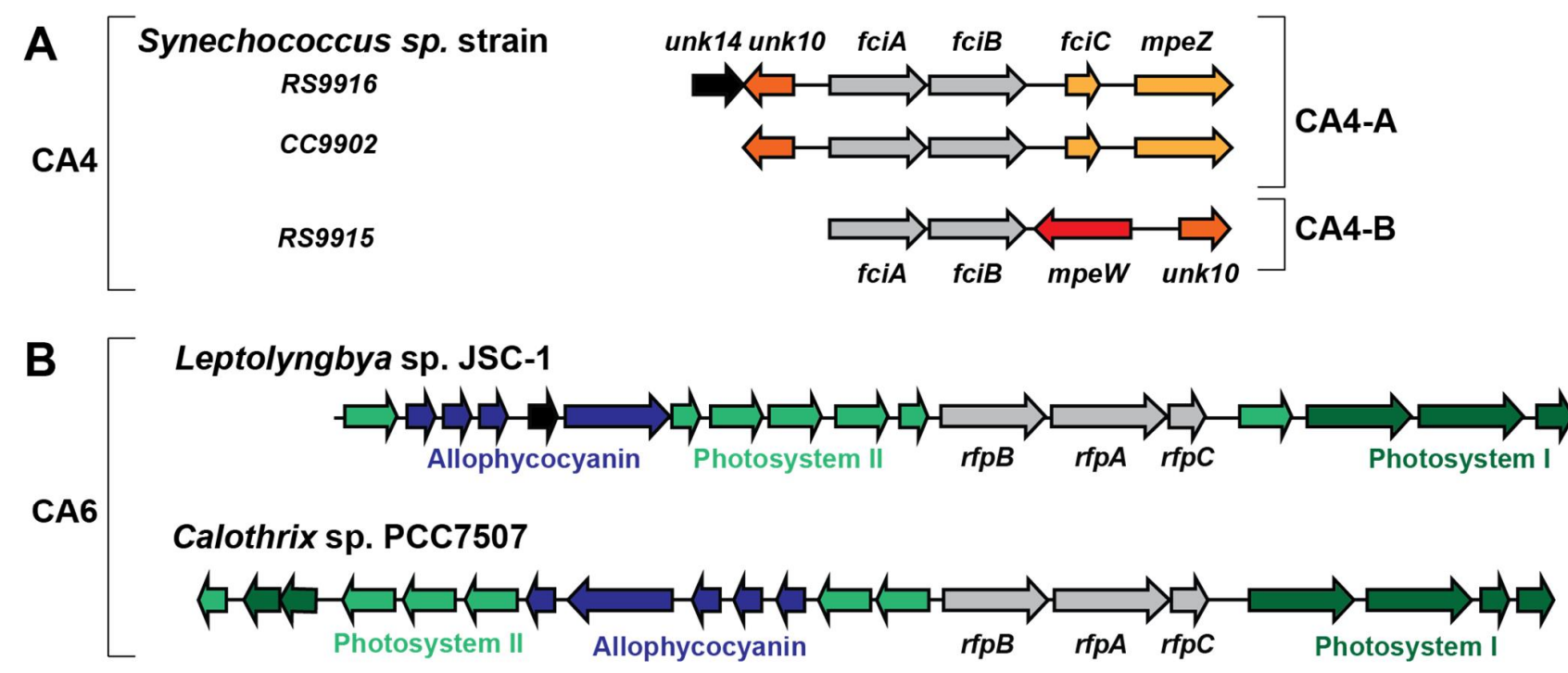

Figure 5. Genomic localization of genes involved in chromatic acclimation. Genomic diversity of exemplar strains capable of (A) CA4 and (B) CA6 (also called FaRLiP). All strains capable of CA4 contain a small genomic island containing $f c i A, f c i B$, unk10, and either mpeZ or mpeW. All strains that contain $m p e Z$ also contain $f c i C$. Strains capable of CA6/FaRLiP contain a large genomic region containing $r f p A, r f p B, r f p C$, and genes encoding far-red-specific allophycocyanin (APC), photosystem II (PSII), and photosystem I (PSI). 


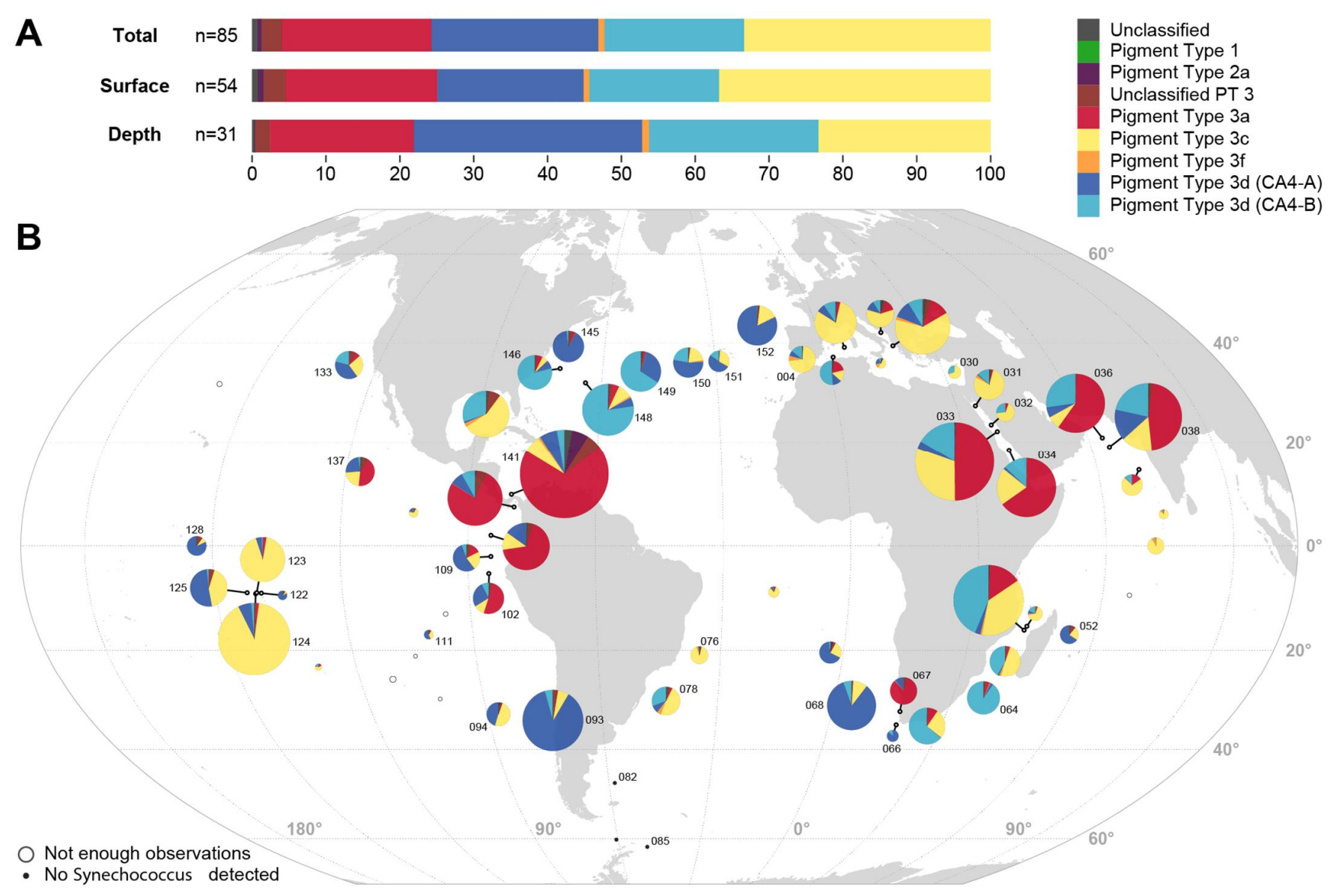

Figure 6. Ecological importance of Synechococcus capable of CA4. (A) Relative abundance of each Synechococcus pigment type (PT) in the whole Tara Oceans dataset (Total), in surface, and at the deep chlorophyll maximum (DCM), as assessed by recruiting reads of three distinct marker genes ( $c p c B A, m p e B A$, and mpeW). (B) Map showing the global distribution of all Synechococcus PTs, including CA4-A (dark blue) and CA4-B (light blue), in surface waters along the Tara Oceans circumnavigation transect [see (42) for details on the other pigment types]. Diameters of pies are proportional to the number of $\angle P C B A$ reads normalized by the sequencing effort. Stations with less than $30 \angle p c B A$ or mpeBA reads are indicated by open circles, and those with no $c p c B A$ reads by black dots. Numbers next to pies correspond to Tara Oceans stations. Reproduced with permission from (42). 


\section{References}

1. Acinas SG, Haverkamp THA, Huisman J, Stal LJ. 2008. Phenotypic and genetic diversification of Pseudanabaena spp. (cyanobacteria). ISME J 3:31-46

2. Alvey RM, Bezy RP, Frankenberg-Dinkel N, Kehoe DM. 2007. A light regulated OmpRclass promoter element coordinates light harvesting protein and chromophore biosynthetic enzyme gene expression. Mol Microbiol 64:319-32

3. Alvey RM, Karty JA, Roos E, Reilly JP, Kehoe DM. 2003. Lesions in phycoerythrin chromophore biosynthesis in Fremyella diplosiphon reveal coordinated light regulation of apoprotein and pigment biosynthetic enzyme gene expression. Plant Cell 15:2448-63

4. Appleby JL, Parkinson JS, Bourret RB. 1996. Signal transduction via the multi-step phosphorelay: Not necessarily a road less traveled. Cell 86:845-8

5. Aravind L, Anantharaman V, Balaji S, Babu MM, lyer LM. 2005. The many faces of the helix-turn-helix domain: Transcription regulation and beyond. FEMS Microbiol Rev 29:231-62

6. Averina S, Velichko N, Senatskaya E, Pinevich A. 2018. Far-red light photoadaptations in aquatic cyanobacteria. Hydrobiologia 813:1-17

7. Behrendt L, Brejnrod A, Schliep M, Sorensen SJ, Larkum AWD, Kuhl M. 2015. Chlorophyll $f$-driven photosynthesis in a cavernous cyanobacterium. ISME J 9:2108-11

8. Bennett A, Bogorad L. 1973. Complementary chromatic adaptation in a filamentous blue-green alga. J Cell Biol 58:419-35

9. Bezy RP, Wiltbank L, Kehoe DM. 2011. Light-dependent attenuation of phycoerythrin gene expression reveals convergent evolution of green light sensing in cyanobacteria. Proc Natl Acad Sci USA 108:18542-7

10. Bordowitz JR, Montgomery BL. 2008. Photoregulation of cellular morphology during complementary chromatic adaptation requires sensor-kinase-class protein RcaE in Fremyella diplosiphon. J Bacteriol 190:4069-74

11. Brown II, Bryant DA, Casamatta D, Thomas-Keprta KL, Sarkisova SA, et al. 2010. Polyphasic characterization of a thermotolerant siderophilic filamentous cyanobacterium that produces intracellular iron deposits. Appl Environ Microbiol 76:6664-72

12. Bussell AN, Kehoe DM. 2013. Control of a four-color sensing photoreceptor by a twocolor sensing photoreceptor reveals complex light regulation in cyanobacteria. Proc NatI Acad Sci USA 110:12834-9

13. Butler WL, Norris KH, Siegelman HW, Hendricks SB. 1959. Detection, assay, and preliminary purification of the pigment controlling photoresponsive development of plants. Proc Natl Acad Sci USA 45:1703-8

14. Chen M, Floetenmeyer M, Bibby TS. 2009. Supramolecular organization of phycobiliproteins in the chlorophyll d-containing cyanobacterium Acaryochloris marina. FEBS Lett 583:2535-9

15. Chiang GG, Schaefer MR, Grossman AR. 1992. Complementation of a red-lightindifferent cyanobacterial mutant. Proc Natl Acad Sci USA 89:9415-9 
16. Cobley JG, Clark AC, Weerasurya S, Queseda FA, Xiao JY, et al. 2002. CpeR is an activator required for expression of the phycoerythrin operon (cpeBA) in the cyanobacterium Fremyella diplosiphon and is encoded in the phycoerythrin linker-polypeptide operon (cpeCDESTR). Mol Microbiol 44:1517-31

17. Collier JL, Palenik B. 2003. Phycoerythrin-containing picoplankton in the Southern California Bight. Deep-Sea Research Part li-Topical Studies in Oceanography 50:2405-22

18. Conley PB, Lemaux PG, Grossman AR. 1985. Cyanobacterial light-harvesting complex subunits encoded in two red light-induced transcripts. Science 230:550-3

19. Conley PB, Lemaux PG, Grossman AR. 1988. Molecular characterization and evolution of sequences encoding light-harvesting components in the chromatically adapting cyanobacterium Fremyella diplosiphon J Mol Biol 199:447-65

20. Deng GP, Liu F, Liu XW, Zhao JD. 2012. Significant energy transfer from CpcG2phycobilisomes to photosystem I in the cyanobacterium Synechococcus sp PCC 7002 in the absence of ApcD-dependent state transitions. FEBS Lett 586:2342-5

21. Diakoff S, Scheibe J. 1973. Action spectra for chromatic adaptation in Tolypothrix tenuis. Plant Physiol 51:382-5

22. Ding WL, Hou YN, Tan ZZ, Jiang SP, Miao D, et al. 2018. Far-red acclimating cyanobacterium as versatile source for bright fluorescent biomarkers. Biochim Biophys Acta-Mol Cell Res 1865:1649-56

23. Duxbury Z, Schliep M, Ritchie RJ, Larkum AWD, Chen M. 2009. Chromatic photoacclimation extends utilisable photosynthetically active radiation in the chlorophyll d-containing cyanobacterium, Acaryochloris marina. Photosynth Res 101:6975

24. Engelmann TW. 1902. Untersuchungen uber die qualitativen Beziehungen zwieschen Absorbtion des Lichtes und Assimilation in Pflanzenzellen. I. Das Mikrospectraphotometer, ein Apparat zur qualitativen Mikrospectralanalyse. II. Experimentelle Grundlangen zur Ermittelung der quantitativen Beziehungen zwieschen Assimilationsenergie und Absorptiongrosse. III. Bestimmung der Vertheilung der Energie im Spectrum von Sonnenlicht mittels Bacterien-Methode und quantitativen Mikrospectralanalyse. Bot Z 42:81-105

25. Everroad C, Six C, Partensky F, Thomas JC, Holtzendorff J, Wood AM. 2006. Biochemical bases of type IV chromatic adaptation in marine Synechococcus spp. J Bacteriol 188:3345-56

26. Federspiel NA, Grossman AR. 1990. Characterization of the light-regulated operon encoding the phycoerythrin-associated linker proteins from the cyanobacterium Fremyella diplosiphon. J Bacteriol 172:4072-81

27. Federspiel NA, Scott L. 1992. Characterization of a light-regulated gene encoding a new phycoerythrin-associated linker protein from the cyanobacterium Fremyella diplosiphon. J Bacteriol 174:5994-8

28. Flombaum P, Gallegos JL, Gordillo RA, Rincon J, Zabala LL, et al. 2013. Present and future global distributions of the marine Cyanobacteria Prochlorococcus and Synechococcus. Proc Natl Acad Sci USA 110:9824-9 
29. Frankenberg N, Mukougawa K, Kohchi T, Lagarias JC. 2001. Functional genomic analysis of the HY2 family of ferredoxin-dependent bilin reductases from oxygenic photosynthetic organisms. Plant Cell 13:965-78

30. Fujita Y, Hattori A. 1960. Effect of chromatic lights on phycobilin formation in a bluegreen alga, Tolypothrix tenuis. Plant Cell Physiol 1:293-303

31. Fujita Y, Hattori A. 1962. Photochemical interconversion between precursors of phycobilin chromoproteids in Tolypothrix tenuis Plant Cell Physiol 3:209-20

32. Fuller NJ, Marie D, Partensky F, Vaulot D, Post AF, Scanlan DJ. 2003. Clade-specific 165 ribosomal DNA oligonucleotides reveal the predominance of a single marine Synechococcus clade throughout a stratified water column in the Red Sea. Appl Env Microbiol 69:2430-43

33. Gaiducov N. 1902. Uber den Einfluss farbigen Lichtes auf die Farbung lebender Oscillatorien. Abh Preuss Akad Wiss V:1-36

34. Gaidukov N. 1903. Die farbervonderung bei den prozessen der komplementoren chromatischen adaptation. Ber Dtsch Bot Ges 21:517-22

35. Gallegos MT, Schleif R, Bairoch A, Hofmann K, Ramos JL. 1997. Arac/XylS family of transcriptional regulators. Microbiol Mol Biol Rev 61:393-410

36. Gan F, Shen G, Bryant DA. 2015. Occurrence of far-red light photoacclimation (FaRLiP) in diverse cyanobacteria. Life-Basel 5:4-24

37. Gan F, Zhang S, Rockwell NC, Martin SS, Lagarias JC, Bryant DA. 2014. Extensive remodeling of a cyanobacterial photosynthetic apparatus in far-red light. Science 345:1312-7

38. Gendel S, Ohad I, Bogorad L. 1979. Control of phycoerythrin synthesis during chromatic adaptation. Plant Physiol 64:786-90

39. Glazer AN. 1989. Light guides. Directional energy transfer in a photosynthetic antenna. J Biol Chem 264:1-4

40. Gloag RS, Ritchie RJ, Chen M, Larkum AWD, Quinnell RG. 2007. Chromatic photoacclimation, photosynthetic electron transport and oxygen evolution in the Chlorophyll $d$-containing oxyphotobacterium Acaryochloris marina. BBA-Bioenergetics 1767:127-35

41. Gomez-Lojero C, Leyva-Castillo LE, Herrera-Salgado P, Barrera-Rojas J, Rios-Castro E, Gutierrez-Cirlos EB. 2018. Leptolyngbya CCM 4, a cyanobacterium with far-red photoacclimation from Cuatro Cienegas Basin, Mexico. Photosynthetica 56:342-53

42. Grebért T, Dore H, Partensky F, Farrant GK, Boss ES, et al. 2018. Light color acclimation is a key process in the global ocean distribution of Synechococcus cyanobacteria. Proc Natl Acad Sci USA 115:E2010-E9

43. Grossman AR, Schaefer MR, Chiang GG, Collier JL. 1993. The phycobilisome, a lightharvesting complex responsive to environmental conditions. Microbiol Mol Biol Rev 57:725-49

44. Gutu A, Kehoe DM. 2011. Emerging perspectives on the mechanisms, regulation, and distribution of light color acclimation in cyanobacteria. Mol Plant 5:1-13

45. Gutu A, Nesbit AD, Alverson AJ, Palmer JD, Kehoe DM. 2013. Unique role for translation initiation factor 3 in the light color regulation of photosynthetic gene expression. Proc Natl Acad Sci USA 110:16253-8 
46. Hattori A, Fujita Y. 1959. Effect of pre-illumination on the formation of phycobilin pigments in a blue-green alga, Tolypothrix tenuis J Biochem 46:1259-61

47. Haury JF, Bogorad L. 1977. Action Spectra for Phycobiliprotein Synthesis in a Chromatically Adapting Cyanophyte, Fremyella diplosiphon. Plant Physiol. 60:835-9

48. Hernandez-Prieto MA, Li YQ, Postier BL, Blankenship RE, Chen M. 2018. Far-red light promotes biofilm formation in the cyanobacterium Acaryochloris marina. Environ Microbiol 20:535-45

49. Herrera-Salgado P, Leyva-Castillo LE, Rios-Castro E, Gomez-Lojero C. 2018. Complementary chromatic and far-red photoacclimations in Synechococcus ATCC 29403 (PCC 7335). I: The phycobilisomes, a proteomic approach. Photosynth Res 138:39-56

50. Hirose Y, Misawa N, Yonekawa C, Nagao N, Watanabe M, et al. 2017. Characterization of the genuine type 2 chromatic acclimation in the two Geminocystis cyanobacteria. DNA Res 24:387-96

51. Hirose Y, Narikawa R, Katyama M, Ikeuchi M. 2010. Cyanobacteriochrome CcaS regulates phycoerythrin accumulation in Nostoc punctiforme, a group II chromatic adaptor. Proc Natl Acad Sci USA 107:8854-9

52. Hirose Y, Rockwell NC, Nishiyama K, Narikawa R, Ukaji Y, et al. 2013. Green/red cyanobacteriochromes regulate complementary chromatic acclimation via a protochromic photocycle. Proc Natl Acad Sci USA 110:4974-9

53. Hirose Y, Shimada T, Narikawa R, Katayama M, Ikeuchi M. 2008. Cyanobacteriochrome $\mathrm{CcaS}$ is the green light receptor that induces the expression of phycobilisome linker protein. Proc Nat Acad Sci USA 105:9528-33

54. Ho MY, Gan F, Shen GZ, Bryant DA. 2017. Far-red light photoacclimation (FaRLiP) in Synechococcus sp PCC 7335. II.Characterization of phycobiliproteins produced during acclimation to far-red light. Photosynth Res 131:187-202

55. Ho MY, Gan F, Shen GZ, Zhao C, Bryant DA. 2017. Far-red light photoacclimation (FaRLiP) in Synechococcus sp PCC 7335: I. Regulation of FaRLiP gene expression. Photosynth Res 131:173-86

56. Hu Q, Marquardt J, Iwasaki I, Miyashita H, Kurano N, et al. 1999. Molecular structure, localization and function of biliproteins in the chlorophyll a/d containing oxygenic photosynthetic prokaryote Acaryochloris marina. Biochim Biophys Acta 1412:250-61

57. Humily F, Farrant GK, Marie D, Partensky F, Mazard S, et al. 2014. Development of a targeted metagenomic approach to study a genomic region involved in light harvesting in marine Synechococcus. FEMS Microbiol Ecol 88:231-49

58. Humily F, Partensky F, Six C, Farrant GK, Ratin M, et al. 2013. A gene island with two possible configurations is involved in chromatic acclimation in marine Synechococcus. Plos One 8:e84459

59. Ikeuchi M, Ishizuka T. 2008. Cyanobacteriochromes: a new superfamily of tetrapyrrolebinding photoreceptors in cyanobacteria. Photochem Photobiol Sci 7:1159-67

60. Itoh S, Ohno T, Noji T, Yamakawa H, Komatsu H, et al. 2015. Harvesting far-red light by chlorophyll $f$ in photosystems I and II of unicellular cyanobacterium strain KC1. Plant Cell Physiol 56:2024-34

61. Kahn K, Mazel D, Houmard J, Tandeau de Marsac N, Schaefer MR. 1997. A role for cpeYZ in cyanobacterial phycoerythrin biosynthesis. J Bacteriol 179:998-1006 
62. Kehoe DM, Grossman AR. 1996. Similarity of a chromatic adaptation sensor to phytochrome and ethylene receptors. Science 273:1409-12

63. Kehoe DM, Grossman AR. 1997. New classes of mutants in complementary chromatic adaptation provide evidence for a novel four-step phosphorelay system. J Bacteriol 179:3914-21

64. Kehoe DM, Gutu A. 2006. Responding to color: The regulation of complementary chromatic adaptation. Annu Rev Plant Biol 57:127-50

65. Kondo K, Geng XX, Katayama M, Ikeuchi M. 2005. Distinct roles of CpcG1 and CpcG2 in phycobilisome assembly in the cyanobacterium Synechocystis sp PCC 6803. Photosynth Res 84:269-73

66. Kondo K, Ochiai Y, Katayama M, Ikeuchi M. 2007. The Membrane-Associated CpcG2Phycobilisome in Synechocystis: A New Photosystem I Antenna. Plant Physiol. 144:120010

67. Li L, Alvey RM, Bezy RP, Kehoe DM. 2008. Inverse transcriptional activities during complementary chromatic adaptation are controlled by the response regulator $\mathrm{RcaC}$ binding to red and green light-responsive promoters. Mol Microbiol 68:286-97

68. Li L, Kehoe DM. 2005. In vivo analysis of the roles of conserved aspartate and histidine residues within a complex response regulator. Mol Microbio/ 55:1538-52

69. Li Y, Vella N, Chen M. 2018. Characterization of isolated photosystem I from Halomicronema hongdechloris, a chlorophyll $f$-producing cyanobacterium. Photosynthetica 56:306-15

70. Li YQ, Lin YK, Garvey CJ, Birch D, Corkery RW, et al. 2016. Characterization of red-shifted phycobilisomes isolated from the chlorophyll f-containing cyanobacterium Halomicronema hongdechloris. BBA-Bioenergetics 1857:107-14

71. Liu HB, Jing HM, Wong THC, Chen BZ. 2014. Co-occurrence of phycocyanin- and phycoerythrin-rich Synechococcus in subtropical estuarine and coastal waters of Hong Kong. Env Microbiol Rep 6:90-9

72. Liu LN, Chen XL, Zhang YZ, Zhou BC. 2005. Characterization, structure and function of linker polypeptides in phycobilisomes of cyanobacteria and red algae: An overview. Biochimica et Biophysica Acta-Bioenergetics 1708:133-42

73. Lomax TL, Conley PB, Schilling J, Grossman AR. 1987. Isolation and characterization of light-regulated phycobilisome linker polypeptide genes and their transcription as a polycistronic mRNA. J Bacteriol 169:2675-84

74. Loughlin PC, Duxbury Z, Mugerwa TTM, Smith PMC, Willows RD, Chen M. 2016. Spectral properties of bacteriophytochrome AM1_5894 in the chlorophyll $d$-containing cyanobacterium Acaryochloris marina. Sci Rep-Uk 6

75. MacColl R. 1998. Cyanobacterial Phycobilisomes. J Struct Biol 124:311-34

76. Majumder ELW, Wolf BM, Liu HJ, Berg RH, Timlin JA, et al. 2017. Subcellular pigment distribution is altered under far-red light acclimation in cyanobacteria that contain chlorophyll $f$. Photosynth Res 134:183-92

77. Marquardt J, Senger H, Miyashita H, Miyachi S, Morschel E. 1997. Isolation and characterization of biliprotein aggregates from Acaryochloris marina, a Prochloron-like prokaryote containing mainly chlorophyll $d$. FEBS Lett 410:428-32 
78. Mazel D, Guglielmi G, Houmard J, Sidler W, Bryant DA, Tandeau de Marsac N. 1986. Green light induces transcription of the phycoerythrin operon in the cyanobacterium Calothrix 7601. Nucleic Acids Res 14:8279-90

79. Mobberley JM, Lindemann SR, Bernstein HC, Moran JJ, Renslow RS, et al. 2017. Organismal and spatial partitioning of energy and macronutrient transformations within a hypersaline mat. FEMS Microbiol Ecol 93:13

80. Montgomery BL, Lechno-Yossef S, Kerfeld CA. 2016. Interrelated modules in cyanobacterial photosynthesis: the carbon-concentrating mechanism, photorespiration, and light perception. $J$ Exp Bot 67:2931-40

81. Narikawa R, Enomoto G, Ni-Ni-Win, Fushimi K, Ikeuchi M. 2014. A new type of dual-cys cyanobacteriochrome GAF domain found in cyanobacterium Acaryochloris marina, which has an unusual red/blue reversible photoconversion cycle. Biochemistry 53:50519

82. Narikawa R, Fushimi K, Ni-Ni-Win, Ikeuchi M. 2015. Red-shifted red/green-type cyanobacteriochrome AM1_1870g3 from the chlorophyll $d$-bearing cyanobacterium Acaryochloris marina. Biochem Bioph Res Co 461:390-5

83. Narikawa R, Nakajima T, Aono Y, Fushimi K, Enomoto G, et al. 2015. A biliverdin-binding cyanobacteriochrome from the chlorophyll $d$-bearing cyanobacterium Acaryochloris marina. Sci Rep-Uk 5:10

84. Nesbit AD, Whippo C, Hangarter RP, Kehoe DM. 2015. Translation initiation factor 3 families: what are their roles in regulating cyanobacterial and chloroplast gene expression? Photosynth Res 126:147-59

85. Oelmuller R, Grossman AR, Briggs WR. 1988. Photoreversibility of the effect of red and green light-pulses on the accumulation in darkness of messenger-RNAs coding for phycocyanin and phycoerythrin in Fremyella diplosiphon. Plant Physiol 88:1084-91

86. Ohki K, Fujita Y. 1978. Photocontrol of phycoerythrin formation in blue-green alga Tolypothrix tenuis growing in the dark. Plant Cell Physiol 19:7-15

87. Ohki K, Watanabe M, Fujita Y. 1982. Action of near UV and blue light on the photocontrol of phycobiliprotein formation: A complementary chromatic adaptation. Plant Cell Physiol 23:651-6

88. Ohkubo S, Miyashita H. 2017. A niche for cyanobacteria producing chlorophyll $f$ within a microbial mat. Isme J 11:2368-78

89. Olson RJ, Chisholm SW, Zettler ER, Armbrust EV. 1990. Pigments, size, and distribution of Synechococcus in the North-Atlantic and Pacific Oceans. Limnol Oceanogr 35:45-58

90. Ong LJ, Glazer AN. 1991. Phycoerythrins of marine unicellular cyanobacteria. I. Bilin types and locations and energy transfer pathways in Synechococcus spp. phycoerythrins. J Biol Chem 266:9515-27

91. Ong LJ, Glazer AN, Waterbury JB. 1984. An unusual phycoerythrin from a marine cyanobacterium. Science 224:80-3

92. Palenik B. 2001. Chromatic adaptation in marine Synechococcus strains. Appl Environ Microbiol 67:991-4

93. Pattanaik B, Busch AWU, Flu PS, Chen J, Montgomery BL. 2014. Responses to iron limitation are impacted by light quality and regulated by RcaE in the chromatically acclimating cyanobacterium Fremyella diplosiphon. Microbiol-Sgm 160:992-1005 
94. Pattanaik B, Montgomery BL. 2010. FdTonB is involved in the photoregulation of cellular morphology during complementary chromatic adaptation in Fremyella diplosiphon. Microbiology-Sgm 156:731-41

95. Pattanaik B, Whitaker MJ, Montgomery BL. 2012. Light quantity affects the regulation of cell shape in Fremyella diplosiphon. Front Microbiol 3

96. Peled-Zehavi H, Danon A. 2007. Translation and translational regulationin chloroplasts. pp 249-281. Berlin Heidelberg: Springer-Verlag

97. Postius C, Neuschaefer-Rube O, Haid V, Boger P. 2001. N 2 -fixation and complementary chromatic adaptation in non-heterocystous cyanobacteria from Lake Constance. FEMS Microbiol Ecol 37:117-25

98. Rockwell NC, Lagarias JC. 2010. A brief history of phytochromes. Chem Phys Chem 11:1172-80

99. Rockwell NC, Su YS, Lagarias JC. 2006. Phytochrome structure and signaling mechanisms. Annu Rev Plant Biol 57:837-58

100. Rohnke BA, Singh SP, Pattanaik B, Montgomery BL. 2018. RcaE-dependent regulation of carboxysome structural proteins has a central role in environmental determination of carboxysome morphology and abundance in Fremyella diplosiphon. Msphere 3

101. Sanfilippo JE, Nguyen AA, Garczarek L, Karty JA, Pokhrel S, et al. Interplay between differentially expressed enzymes contributes to light color acclimation in marine Synechococcus. Proc Nat Acad Sci USA Submitted

102. Sanfilippo JE, Nguyen AA, Karty JA, Shukla A, Schluchter WM, et al. 2016. Self-regulating genomic island encoding tandem regulators confers chromatic acclimation to marine Synechococcus. Proc Natl Acad Sci USA 113:6077-82

103. Scheer H, Zhao KH. 2008. Biliprotein maturation: the chromophore attachment. Mol Microbiol 68:263-76

104. Schleif R. 2010. AraC protein, regulation of the l-arabinose operon in Escherichia coli, and the light switch mechanism of AraC action. FEMS Microbiol Rev 34:779-96

105. Seib LO, Kehoe DM. 2002. A turquoise mutant genetically separates expression of genes encoding phycoerythrin and its associated linker peptides. J Bacteriol 184:962-70

106. Shui J, Saunders E, Needleman R, Nappi M, Cooper J, et al. 2009. Light-dependent and light-independent protochlorophyllide oxidoreductases in the chromatically adapting cyanobacterium Fremyella diplosiphon UTEX 481. Plant Cell Physiol 50:1507-21

107. Shukla A, Biswas A, Blot N, Partensky F, Karty JA, et al. 2012. Phycoerythrin-specific bilin lyase-isomerase controls blue-green chromatic acclimation in marine Synechococcus. Proc Natl Acad Sci USA 109:20136-41

108. Singh SP, Montgomery BL. 2012. Reactive oxygen species are involved in the morphology-determining mechanism of Fremyella diplosiphon cells during complementary chromatic adaptation. Microbiol-Sgm 158:2235-45

109. Singh SP, Montgomery BL. 2014. Morphogenes bolA and mreB mediate the photoregulation of cellular morphology during complementary chromatic acclimation in Fremyella diplosiphon. Mol Microbiol 93:167-82

110. Singh SP, Montgomery BL. 2015. Regulation of BolA abundance mediates morphogenesis in Fremyella diplosiphon. Front Microbiol 6 
111. Six C, Thomas JC, Garczarek L, Ostrowski M, Dufresne A, et al. 2007. Diversity and evolution of phycobilisomes in marine Synechococcus spp.: a comparative genomics study. Genome Biol 8:R259

112. Stomp M, Huisman J, Stal LJ, Matthijs HCP. 2007. Colorful niches of phototrophic microorganisms shaped by vibrations of the water molecule. ISME J 1:271-82

113. Stomp M, van Dijk MA, van Overzee HM, Wortel MT, Sigon CA, et al. 2008. The timescale of phenotypic plasticity and its impact on competition in fluctuating environments. Am Nat 172:E169-E85

114. Stowe WC, Brodie-Kommit J, Stowe-Evans E. 2011. Characterization of Complementary Chromatic Adaptation in Gloeotrichia UTEX 583 and Identification of a Transposon-like Insertion in the cpeBA Operon. Plant Cell Physiol 52:553-62

115. Stowe-Evans EL, Ford J, Kehoe DM. 2004. Genomic DNA microarray analysis: Identification of new genes regulated by light color in the cyanobacterium Fremyella diplosiphon. J Bacteriol 186:4338-49

116. Sunagawa S, Coelho LP, Chaffron S, Kultima JR, Labadie K, et al. 2015. Structure and function of the global ocean microbiome. Science 348

117. Tandeau de Marsac N. 1977. Occurrence and nature of chromatic adaptation in cyanobacteria. J Bacteriol 130:82-91

118. Tandeau de Marsac N, Cohen-Bazire G. 1977. Molecular composition of cyanobacterial phycobilisomes. Proc Natl Acad Sci USA 74:1635-9

119. Terauchi K, Montgomery BL, Grossman AR, Lagarias JC, Kehoe DM. 2004. RcaE is a complementary chromatic adaptation photoreceptor required for green and red light responsiveness. Mol Microbiol 51:567-77

120. Thompson AW, van den Engh G. 2016. A multi-laser flow cytometry method to measure single cell and population-level relative fluorescence action spectra for the targeted study and isolation of phytoplankton in complex assemblages. Limnol Oceanogr-Meth 14:39-49

121. Tobes R, Ramos JL. 2002. AraC-XyIS database: a family of positive transcriptional regulators in bacteria. Nucleic Acids Res 30:318-21

122. Vogelmann TC, Scheibe J. 1978. Action spectra for chromatic adaptation in the bluegreen alga Fremyella diplosiphon Planta 143:233-9

123. Watabe K, Mimuro M, Tsuchiya T. 2015. Establishment of the forward genetic analysis of the chlorophyll $d$-dominated cyanobacterium Acaryochloris marina MBIC 11017 by applying in vivo transposon mutagenesis system. Photosynth Res 125:255-65

124. Watanabe M, Ikeuchi M. 2013. Phycobilisome: architecture of a light-harvesting supercomplex. Photosynth Res 116:265-76

125. Watanabe M, Semchonok DA, Webber-Birungi MT, Ehira S, Kondo K, et al. 2014. Attachment of phycobilisomes in an antenna-photosystem I supercomplex of cyanobacteria. Proc Natl Acad Sci USA 111:2512-7

126. Wiethaus J, Busch AWU, Dammeyer T, Frankenberg-Dinkel N. 2010. Phycobiliproteins in Prochlorococcus marinus: Biosynthesis of pigments and their assembly into proteins. Eur J Cell Biol 89:1005-10 
127. Wiltbank LB, Kehoe DM. 2016. Two cyanobacterial photoreceptors regulate photosynthetic light harvesting by sensing teal, green, yellow and red light. mBio 7:e02130-15

128. Wiltbank LB, Kehoe DM. 2019. Diverse light responses of cyanobacteria mediated by phytochrome superfamily photoreceptors. Nat Rev Microbiol 17:37-50

129. Wood AM, Horan PK, Muirhead K, Phinney DA, Yentsch CM, Waterbury JB. 1985. Discrimination between types of pigments in marine Synechococcus spp. by scanning spectroscopy, epifluorescence microscopy, and flow-cytometry. Limnol Oceanogr 30:1303-15

130. Xia XM, Partensky F, Garczarek L, Suzuki K, Guo C, et al. 2017. Phylogeography and pigment type diversity of Synechococcus cyanobacteria in surface waters of the northwestern Pacific Ocean. Environ Microbiol 19:142-58

131. Xu QZ, Han JX, Tang QY, Ding WL, Miao D, et al. 2016. Far-red light photoacclimation: Chromophorylation of FR induced alpha- and beta-subunits of allophycocyanin from Chroococcidiopsis thermalis sp PCC7203. Biochim Biophys Acta-Bioenerg 1857:1607-16

132. Zhao C, Gan F, Shen GZ, Bryant DA. 2015. RfpA, RfpB, and RfpC are the master control elements of far-red light photoacclimation (FaRLiP). Front Microbiol 6 